\title{
Corn and Soybean Host Root Endophytic Fungi with Toxicity Toward the Soybean Cyst Nematode
}

\author{
Noah Strom, ${ }^{1}$ Weiming Hu, ${ }^{2}$ Deepak Haarith, ${ }^{3}$ Senyu Chen, ${ }^{4}$ and Kathryn Bushley ${ }^{1, \dagger}$ \\ ${ }^{1}$ Department of Plant and Microbial Biology, University of Minnesota, Saint Paul, MN \\ ${ }^{2}$ Entomology and Nematology Department, University of Florida, Gainesville, FL \\ ${ }^{3}$ Department of Plant Pathology, University of Minnesota, Saint Paul, MN \\ ${ }^{4}$ Southern Research and Outreach Center, University of Minnesota, Waseca, MN \\ Accepted for publication 16 October 2019.
}

ABSTRACT

\begin{abstract}
Although fungal endophytes are commonly investigated for their ability to deter microbial plant pathogens, few studies have examined the activity of fungal root endophytes against nematodes. The soybean cyst nematode (SCN; Heterodera glycines), the most severe yield-limiting pathogen of soybean (Glycine max), is commonly managed through rotation of soybean with corn (Zea mays), a nonhost of the SCN. A total of 626 fungal endophytes were isolated from surface-sterilized corn and soybean roots from experimental plots in which soybean and corn had been grown under annual rotation and under $1,3,5$, and 35 years of continuous monoculture. Fungal isolates were grouped into 401 morphotypes, which were clustered into 108 operational taxonomic units (OTUs) based on 99\% sequence similarity of the full internal transcribed spacer region. Morphotype representatives within each OTU were grown in malt extract broth and in a
\end{abstract}

secondary metabolite-inducing medium buffered with ammonium tartrate, and their culture filtrates were tested for nematicidal activity against SCN juveniles. A majority of OTUs containing isolates with nematicidal culture filtrates were in the order Hypocreales, with the genus Fusarium being the most commonly isolated nematicidal genus from corn and soybean roots. Less commonly isolated taxa from soybean roots included the nematophagous fungi Hirsutella rhossiliensis, Metacordyceps chlamydosporia, and Arthrobotrys iridis. Root endophytic fungal diversity in soybean was positively correlated with SCN density, suggesting that the SCN plays a role in shaping the soybean root endophytic community.

Keywords: crop rotation, endophytes, fungal communities, monoculture, soybean cyst nematode
Fungal endophytes are increasingly seen as potentially beneficial plant symbionts (Domka et al. 2019; Hardoim et al. 2015) and are a subject of current efforts in bioprospecting for sources of new secondary metabolites (Alvin et al. 2014; Strobel and Daisy 2003; Suryanarayanan et al. 2009). Endophytic fungi play diverse roles in plant health, including improving tolerance to drought (Khan et al. 2011), salt (Waller et al. 2005), cold (Redman et al. 2011), heat (Khan et al. 2012), and toxic metals (Yamaji et al. 2016); enhanced nutrient acquisition (Yadav et al. 2010); improved growth (Redman et al. 2001; Yamaji et al. 2016); disease resistance (Franken 2012; Waller et al. 2005); and herbivore resistance (Latch 1993). Given the difficulty in distinguishing truly nonpathogenic fungi from latent pathogens, we follow Hardoim et al. (2015) in defining an endophyte in this study simply as a fungus that lives at least part of its life inside the plant, a definition that may include fungi along the mutualist-pathogen continuum (Schulz and Boyle 2005).

Multiple factors may shape the composition of endophyte communities in roots. These include abiotic factors such as soil type (Bokati et al. 2016) and biotic factors relating to the plant host such as plant developmental stage (Rothen et al. 2017; Van Overbeek and Van Elsas 2008), plant tissue type (Renuka and Ramanujam 2016; Russo et al. 2016; Yang et al. 2018), and plant genotype (Lundberg et al. 2012; Russo et al. 2016). Several

†Corresponding author: K. Bushley; kbushley@umn.edu

Funding: This work was supported by the U.S. Department of Agriculture National Institute of Food and Agriculture (grant 2015-67013-23419) and the Minnesota Soybean Research and Production Council.

*The $\boldsymbol{e}$-Xtra logo stands for "electronic extra" and indicates that two supplementary figures and four supplementary tables are published online.

The author(s) declare no conflict of interest.

(c) 2020 The American Phytopathological Society culture-dependent (CD) and culture-independent (CI) studies have attempted to characterize the root endophyte community of corn (Zea mays L.) and soybean [Glycine max (L.) Merr.]. Among these studies, many have shown the corn community to be dominated by the genera Fusarium (Amin 2013; Bokati et al. 2016; Potshangbam et al. 2017; Russo et al. 2016) and Alternaria (Bokati et al. 2016; Orole and Adejumo 2011). Several studies also suggest that the soybean root endophyte community is dominated by the genus Fusarium (Fernandes et al. 2015; Russo et al. 2016; Yang et al. 2018). Some studies suggest that root tips may harbor distinct endophyte communities from other sections of the root (Compant et al. 2005; Kawasaki et al. 2016); yet to our knowledge, no endophyte studies of corn and soybean have sampled this environment.

Studies on the roles of root endophytic fungi in the antagonism of plant parasitic nematodes are scarce (Schouten 2016), but some research suggests that these fungi play significant roles in protecting plants from nematodes. For example, Hallmann and Sikora (1994) isolated several endophytic strains of $F$. oxysporum from roots of tomato plants that showed increased resistance to the root-knot nematode (Meloidogyne incognita) and found that many of these strains produced secondary metabolites that killed Meloidogyne incognita juveniles (Hallmann and Sikora 1996). The root endophyte Piriformospora indica was shown to antagonize the sugar beet nematode (Heterodera schachtii) in Arabidopsis species via fungal exudates and cell wall extracts (Daneshkhah et al. 2013). Piriformospora indica was shown to decrease egg density of the soybean cyst nematode (SCN; Heterodera glycines Ichinohe) in a greenhouse trial (Bajaj et al. 2015). Fungi may control nematode pathogens through direct parasitism or through production of metabolites with nematoxic or nematostatic bioactivity (Anke et al. 1995; Degenkolb and Vilcinskas 2016a, b; Meyer 2018; Meyer et al. 1990). However, the role of naturally occurring fungal root endophytes in 
antagonizing nematodes through antibiosis has not been well explored (Schouten 2016).

The $\mathrm{SCN}$ is the most serious soybean pathogen, worldwide. The survival form of the SCN is an egg-filled cyst that can survive in the soil for nearly a decade in the absence of a susceptible plant host (Inagaki and Tsutsumi 1971). The infectious form of the SCN is a second-stage juvenile (J2), which emerges from eggs in SCN cysts in response to a hatching stimulus (Riga et al. 2001). In order to complete their life cycle, J2s infect the roots of susceptible plants, draining photosynthates and causing an estimated $\$ 1.5$ billion in soybean yield losses in the United States every year (Koenning and Wrather 2010). Although rotation to nonhost crops, most commonly corn, is often utilized to minimize SCN populations, the SCN is virtually impossible to eliminate from fields in which it has become established owing to the longevity of SCN cysts (Chen 2011; Inagaki and Tsutsumi 1971). While SCN-resistant varieties of soybean are available, repeated planting leads to the evolution of SCN races that can infect previously resistant varieties (Chen 2011).

With the banning of several important chemical nematicides, biological control has come to be seen as a potential alternative method to manage the SCN (Chen 2004; Kerry 2000; Preston et al. 2003; United Nations Environment Programme 2015; Warnock et al. 2017). Many studies have shown that continuous soybean monoculture leads to the development of microbial soil communities suppressive to the SCN (Hu et al. 2017a; Hussain et al. 2018). Several fungal antagonists of the SCN have been isolated from SCN cysts and juveniles collected from bulk soils (Carris et al. 1989; Chen and Chen 2002; Chen et al. 2000a; Kim and Riggs 1994). However, soybean roots may be a more attractive agroecosystem compartment in which to search for SCN biocontrol agents, because fungi living in the root are well positioned to intercept invading SCN J2s. Likewise, corn roots, although not hosts of the SCN, may nonetheless facilitate establishment of endosphere-competent microbes in the bulk soil (Bardgett and Wardle 2010; Bever 1994; van de Voorde et al. 2011). Because corn is commonly planted in rotation with soybean, it is useful to understand whether the corn endosphere harbors similar or distinct fungal antagonists of the SCN as compared with soybean.

In this study, fungal endophyte communities of roots of corn and soybean under short-term rotations and long-term monocultures were characterized using a $\mathrm{CD}$ method, and select isolates were screened for nematicidal activity against the SCN. The objectives of this study were (i) to examine the role of crop host, crop sequence treatment, and SCN density in shaping the culturable fungal endophyte community of corn and soybean roots; (ii) to explore endophyte communities found in the root tip; and (iii) to identify fungi that produce culture filtrates with nematicidal activity against the SCN. We hypothesized that (i) corn and soybean roots would harbor distinct root endophytic communities and (ii) soybean would host a greater number of nematicidal endophytes than corn, especially under long-term monoculture.

\section{MATERIALS AND METHODS}

Experimental design. This study utilized a long-term cornsoybean rotation experiment at the University of Minnesota Southern Research and Outreach Center in which corn and soybean have been planted continuously, since 1982, under various crop sequences (Crookston et al. 1991) on a Nicollet clay loam (fineloamy, mixed, mesic Aquic Hapludoll) (Soil Survey Staff 2014). The crop varieties were $B t$ corn (Dekalb 50-82) and SCNsusceptible soybean (Pioneer 91Y90). The crop sequences included long-term corn and soybean monocultures (Cc and Ss), 5-year rotations in which years 1 through 5 of corn (C1 to $\mathrm{C} 5)$ were followed by years 1 through 5 of soybean (S1 to S5), and annual rotations in which corn and soybean were alternately planted each year ( $\mathrm{Ca}$ and $\mathrm{Sa}$ ). There were four replicates for each crop sequence treatment, and plots were arranged in a randomized complete block design. A complete description of the experimental plots and their management is available elsewhere (Grabau and Chen 2016a, b; Hu et al. 2018). For this study, roots were sampled from experimental plots under the following crop sequence treatments: C1, C3, C5, Cc, $\mathrm{Ca}, \mathrm{S} 1, \mathrm{~S} 3, \mathrm{~S} 5, \mathrm{Ss}$, and Sa. SCN density was measured at midseason as eggs/100 $\mathrm{cm}^{3}$ of soil, and yield was measured at harvest as reported in Hu et al. (2018) and Strom et al. (2019b).

Sample collection. Midseason root samples were collected on 21 July 2016. Sampling of roots followed the same protocol described in Strom et al. (2019a) and is briefly described, here. Six corn plants and six groups of three to four soybean plants were removed from evenly spaced locations in each treatment plot using a spade. Soil was removed from the root systems by hand. Three lateral roots $<2 \mathrm{~mm}$ in diameter and approximately 6 to $9 \mathrm{~cm}$ in length were randomly selected and removed from each root system for a total of 18 lateral roots per plot. The remaining soil was removed by agitating lateral roots in phosphate-buffered saline (PBS) buffer (PBS-S; $130 \mathrm{mM}$ of $\mathrm{NaCl}, 7 \mathrm{mM}$ of $\mathrm{Na}_{2} \mathrm{HPO}_{4}, 3 \mathrm{mM}$

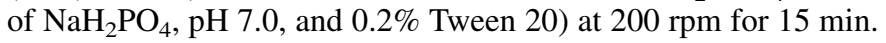
Roots were then rinsed under tap water, agitated twice in sterile double distilled water $\left(\mathrm{ddH}_{2} \mathrm{O}\right)$, and stored at $4{ }^{\circ} \mathrm{C}$ until further processing. All roots were surface sterilized and plated within 2 days.

Isolation and culturing of root endophytes. Prior to collecting root samples for this study, the root surface sterilization protocol was optimized using roots from the same experimental plots. After agitation in PBS buffer and sterile $\mathrm{ddH}_{2} \mathrm{O}$, select root sections were surface sterilized in $0.6 \% \mathrm{NaOCl}$ for between $0 \mathrm{~s}$ and $5 \mathrm{~min}$, followed by three rinses in sterile $\mathrm{ddH}_{2} \mathrm{O}$. Root surface sterility was tested by briefly touching hypochlorite-treated roots to the agar surface of a Petri plate containing one-quarter strength potato dextrose agar plus $50 \mathrm{ppm}$ of chlorotetracycline and $50 \mathrm{ppm}$ of streptomycin (one-quarter APDA) and observing the plates for fungal growth over a period of 2 weeks. No fungal growth was observed on imprint plates for roots with as few as $10 \mathrm{~s}$ of soaking in $0.6 \% \mathrm{NaOCl}$, but fungal growth was observed on positive control plates to which root sections had been added. However, a longer soaking period of 2 min was chosen based on a literature review (Fernandes et al. 2015; Orole and Adejumo 2011) and to reduce the chance of surface contamination. Following the optimized protocol, 18 soil-free lateral roots from each experimental plot were sterilized by soaking them in $10 \%$ bleach solution $(0.6 \% \mathrm{NaOCl})$ for $2 \mathrm{~min}$ followed by three rinses in sterile $\mathrm{dd}_{2} \mathrm{O}$. Surface-sterilized roots were allowed to dry on a sterile paper towel for $1 \mathrm{~min}$ prior to plating.

A flame-sterilized scalpel was used to cut one 2- to 5-mm section from either the center or tip of each surface-sterilized lateral root. A majority of sections were taken from central regions along the length of the root, but 3 of 18 sections were taken from the tips of lateral roots from each plot. One individual root section was plated per 10-cm-diameter Petri plate containing one-quarter APDA. Plates were sealed with Parafilm and incubated at room temperature for 3 months in ambient light. The plates were checked for fungal growth every 3 days for the first 2 weeks and once per week thereafter.

Half-centimeter-wide plugs of fungal colonies growing from root sections were transferred to full-strength potato dextrose agar plus $50 \mathrm{ppm}$ of chlorotetracycline and $50 \mathrm{ppm}$ of streptomycin (APDA) in 10-cm-diameter Petri plates. For root sections in which more than one distinct fungal colony had grown, a mycelial plug was transferred from each colony to a new plate. When fungal colonies on APDA covered one-half to two-thirds of the plate, they were grouped by morphology into morphogroups. One representative isolate for every five isolates from each morphogroup was photographed and selected as a morphotype, and one mycelial plug from each morphotype was transferred to one-quarter APDA covered in sterile cellophane. After colonies covered one-half to two-thirds of the plate, a sterile scalpel was used to transfer half of 
each colony to a cryovial containing $20 \%$ glycerol, which was stored at $-80^{\circ} \mathrm{C}$. The other half of each colony was transferred to a sterile microcentrifuge tube and lyophilized for $48 \mathrm{~h}$ prior to DNA extraction.

Root endophyte DNA extraction, amplification, and bioinformatics. Lyophilized fungal tissue was ground using a sterile pipette tip, and DNA was extracted from a small fragment of ground tissue using the Sigma REDExtract-N-Amp kit, following the manufacturer's protocol. The internal transcribed spacer (ITS) region of fungal rDNA was amplified in 25- $\mu$ l PCR reactions containing $13.5 \mu \mathrm{l}$ of nuclease-free water, $10 \mu \mathrm{l}$ of REDExtract$\mathrm{N}$-Amp PCR Reaction Mix, $0.5 \mu \mathrm{l}$ each of $10 \mu \mathrm{M}$ ITS1F (CTTGGTCATTTAGAGGAAGTAA) and ITS4 (TCCTCCGCT TATTGATATGC) primers, and $0.5 \mu$ of template DNA per sample. PCR parameters were as follows: $94^{\circ} \mathrm{C}$ for $10 \mathrm{~min}$ for initial denaturation followed by 35 cycles of $94^{\circ} \mathrm{C}$ for $1 \mathrm{~min}, 53^{\circ} \mathrm{C}$ for $40 \mathrm{~s}$, and $72^{\circ} \mathrm{C}$ for $1 \mathrm{~min}$, followed by one final extension step at $72^{\circ} \mathrm{C}$ for $10 \mathrm{~min}$. Negative controls containing nuclease-free water in place of template DNA were used in every cycle.

The success of each PCR reaction was visualized through gel electrophoresis. For failed PCR reactions, the DNA sample was diluted by factors of 10 until PCR was successful. PCR products were stored at $-20^{\circ} \mathrm{C}$ until sequencing. Fifteen microliters of each PCR product was submitted to MCLAB (South San Francisco, CA) for cleanup and Sanger sequencing in both forward and reverse directions. Sequences were trimmed using a custom Python script, dhtrim.py (Byun and Haarith 2018), which trims the ends of sequences containing poor-quality base calls. Sequences that did not pass the quality controls set by dhtrim.py were trimmed and edited by hand in BioEdit (Hall 1999), calling ambiguous bases where possible. DNA associated with poor-quality sequences that could not be edited was resequenced. Trimmed forward and reverse reads were aligned using the "pairwise align DNA" function at http://www.bioinformatics.org/sms2. Aligned sequences with $99 \%$ sequence similarity were clustered into operational taxonomic units (OTUs) using USEARCH (Edgar 2010) implemented in QIIME (Caporaso et al. 2010). Species-level taxonomy was assigned to OTUs with a minimum of $97 \%$ sequence similarity, according to BLAST (Altschul et al. 1990), to reference sequences in the UNITE fungal ITS sequence database (Nilsson et al. 2019). For queried sequences matching reference sequences with $<97 \%$ identity and for queried sequences matching multiple reference sequences with differing species-level taxonomy, only the genus name or higher taxonomic level is reported.

Preparation of culture filtrates of fungi. A minimum of $10 \%$ of morphotype representatives from each OTU were tested for nematicidal activity. Selected isolates were recovered from glycerol stocks by plating small amounts of preserved mycelium on onequarter-strength cornmeal agar. After 2 weeks of growth, spores were collected from the surface of the plates using sterile $0.2 \%$ Tween, and the number of spores per milliliter was quantified using a hemacytometer. One million spores-or for nonsporulating isolates, a $1-\mathrm{cm}^{2}$ mycelial block cut into 25 smaller blocks with a sterile scalpel-were added to $125-\mathrm{ml}$ flasks containing $50 \mathrm{ml}$ of sterile malt extract broth (MEB) or secondary metabolite-inducing media with ammonium tartrate (SMAT) [30 $\mathrm{g}$ of fructose, $1.04 \mathrm{~g}$ of $\mathrm{MgSO}_{4} \cdot 7 \mathrm{H}_{2} \mathrm{O}, 0.13 \mathrm{~g}$ of $\mathrm{CaCl}_{2} \cdot 2 \mathrm{H}_{2} \mathrm{O}, 10.04 \mathrm{~g}$ of $\left(\mathrm{NH}_{4}\right)_{2} \mathrm{C}_{4} \mathrm{H}_{4} \mathrm{O}_{6}$, $0.75 \mathrm{~g}$ of $\mathrm{KH}_{2} \mathrm{PO}_{4}, 1 \mathrm{ml}$ of trace elements (trace element composition: $4.4 \mathrm{~g}$ of $\mathrm{ZnSO}_{4} \cdot 7 \mathrm{H}_{2} \mathrm{O}, 180 \mathrm{mg}$ of $\mathrm{MnCl}_{2} \cdot 4 \mathrm{H}_{2} \mathrm{O}$, $25 \mathrm{mg}$ of $\mathrm{NaMoO}_{4}, 80 \mathrm{mg}$ of $\mathrm{CuSO}_{4} \cdot 5 \mathrm{H}_{2} \mathrm{O}, 5 \mathrm{~g}$ of $\mathrm{FeSO}_{4} \cdot 7 \mathrm{H}_{2} \mathrm{O}$ in 1 liter of $\mathrm{ddH}_{2} \mathrm{O}$ ), and $6 \mathrm{~g}$ of L-Valine per 1 liter of $\mathrm{ddH}_{2} \mathrm{O}$ ], which was modified from Lee et al. (2008) by replacing ammonium sulfate with ammonium tartrate as a $\mathrm{pH}$ buffer. Before inoculation with fungi, MEB media had an average $\mathrm{pH}$ of 5.1 and SMAT media had an average $\mathrm{pH}$ of 5.5 .

Liquid cultures were incubated at $25^{\circ} \mathrm{C}$ for 2 weeks at $125 \mathrm{rpm}$ in ambient light. Filtrates were collected by first pouring liquid cultures through two layers of Miracloth into 50-ml centrifuge tubes. These were spun at $3,220 \times g$ for 20 min to settle out fungal spores. Then the liquid fraction was sterile filtered by pushing it through $0.2-\mu \mathrm{m}$ filters using a syringe. Filtrates were stored at $4^{\circ} \mathrm{C}$ overnight. The $\mathrm{pH}$ of a 1-ml sample of each filtrate was measured using a GeneMate $\mathrm{pH}$ meter. After setting up a bioassay, filtrates were stored at $-20^{\circ} \mathrm{C}$.

In vitro screening assay of nematicidal activity of fungal culture filtrates. Cysts of SCN HG type 0 (race 3 ) were extracted from soybean roots from a pot soil culture in a growth room at the Southern Research and Outreach Center. Cysts were washed with running distilled water over a \#60 wire filter. The cysts were then transferred to a 50-ml tube, and debris was removed by drawing it up with a disposable plastic bulb. Debris-free cysts were placed in a sterile $250-\mathrm{ml}$ flask with $50 \mathrm{ml}$ of sterile $\mathrm{ddH}_{2} \mathrm{O}, 250 \mu \mathrm{l}$ of Fungin, $50 \mathrm{ppm}$ of chlorotetracycline, and $100 \mathrm{ppm}$ of streptomycin and incubated overnight at $25^{\circ} \mathrm{C}$. They were then transferred to a new 50 - $\mathrm{ml}$ tube, rinsed three times in sterile $\mathrm{dd}_{2} \mathrm{O}$, and stored at $4^{\circ} \mathrm{C}$ in sterile $\mathrm{ddH}_{2} \mathrm{O}$.

A J2 hatching apparatus was created by placing four layers of sterile coffee filters over a wire screen in a plastic container containing $4 \mathrm{mM}$ of $\mathrm{ZnCl}_{2}$ solution (Chen et al. 2000b). Several hundred sterile SCN cysts were added to the filters, and the apparatus was incubated at $25^{\circ} \mathrm{C}$. $\mathrm{J} 2 \mathrm{~s}$ that emerged over 2 days were collected in two 50-ml tubes, which were spun at 1,500 rpm for 1 min to settle J2s. The supernatant was removed and replaced by $1 \%$ bleach solution $(0.06 \% \mathrm{NaOCl})$, in which the $\mathrm{J} 2 \mathrm{~s}$ were soaked for $5 \mathrm{~min}$. This $\mathrm{J} 2$ suspension was then poured over a $15-\mu \mathrm{m}$ mesh, and the $\mathrm{J} 2 \mathrm{~s}$ retained by the mesh were rinsed three times with sterile $\mathrm{ddH}_{2} \mathrm{O}$. J2s were then transferred to a new 50-ml tube and diluted to $500 \mathrm{~J} 2 / \mathrm{ml}$.

Approximately $50 \mathrm{~J} 2 \mathrm{~s}(0.1 \mathrm{ml}$ of $\mathrm{J} 2$ suspension $)$ and $1 \mathrm{ml}$ of fungal culture filtrate were added to each well of a 24-well plate. Four replicate wells were used for each timepoint for each filtrate. Fungal filtrate-free media spanning a broad $\mathrm{pH}$ range were used as negative controls. J2 viability was assessed at $6,24,48$, and $72 \mathrm{~h}$ by adding two drops of $1 \mathrm{~N}$ of $\mathrm{NaOH}$, which acts as a $\mathrm{J} 2$ stimulus (Chen and Dickson 2000), and observing the J2s' response under an inverted microscope. J2s that remained straight and showed no movement for up to $5 \mathrm{~min}$ were considered dead or paralyzed, whereas those that changed body shape to ring, hook, or S shaped were considered alive. SMAT culture filtrates that were nematicidal and whose $\mathrm{pH}$ was $<5$ or $>8$ were later thawed at $4{ }^{\circ} \mathrm{C}$ and neutralized by adding small amounts of sterile $5 \mathrm{~N} \mathrm{HCl}$ or $\mathrm{NaOH}$. The thawed and neutralized filtrates were then retested against J2s at the 72-h timepoint.

These bioassays were repeated for 12 isolates that had high nematicidal activity in SMAT or MEB to assess reproducibility. For the second trial, fresh SMAT filtrates above $\mathrm{pH} 8$ were not frozen and were neutralized and assayed for nematicidal activity at the same time as fresh non-neutralized SMAT filtrates.

Statistical analyses. All statistical analyses were performed in $\mathrm{R}$ version 3.5.0. Bray-Curtis dissimilarity between endophyte communities was calculated using Hellinger-transformed OTU counts (Legendre and Gallagher 2001). The effect of crop host and crop sequence on community dissimilarity was determined using adonis (Anderson 2001; Oksanen et al. 2016). OTU richness was calculated in the Phyloseq package (McMurdie and Holmes 2013). The abundance of taxa was compared between crop hosts using the Wilcoxon rank-sum test (Wilcoxon 1945) and across crop sequences within each host using the Kruskal-Wallis test (Kruskal and Wallis 1952). Spearman correlation tests were used to compare species' abundance to crop yield and SCN density.

Percentages of $\mathrm{J} 2 \mathrm{~s}$ killed or paralyzed by filtrates of each fungal isolate were compared with the percentage killed or paralyzed in media controls in the same $\mathrm{pH}$ range using the "nparcomp" function, a nonparametric equivalent of a Dunnett test, in the R package, nparcomp (Konietschke et al. 2015). We only considered SMAT filtrates to be nematicidal if they met three criteria: (i) $>50 \%$ 
mortality of J2s at $72 \mathrm{~h}$, (ii) a significant $(P<0.05)$ Dunnett's test comparing nematicidal activity of a filtrate to the SMAT control at the same $\mathrm{pH}$ range, and (iii) if originally outside a $\mathrm{pH}$ range of 5 to 8 , some nematicidal activity was retained when the filtrate was neutralized to between $\mathrm{pH} 5$ and 8 . The proportion of isolates that produced nematicidal culture filtrates per plot was compared between crop hosts, across crop sequences, and against SCN density for each crop using the Wilcoxon rank-sum test, the Kruskal-Wallis test, and Spearman correlations, respectively.

\section{RESULTS}

Corn and soybean roots host distinct fungal endophyte communities. We isolated 626 individual fungal endophytes from surface-sterilized corn and soybean roots over an incubation period of 3 months. These were grouped into 401 morphogroups, which were clustered based on ITS sequencing into 108 OTUs with 69 unique taxonomic assignments. The corn root community was dominated by Setophoma terrestris (syn. Pyrenochaeta terrestris) (35\% of isolates), followed by F. oxysporum (18\%) and Periconia macrospinosa $(16 \%)$, whereas the soybean root community was dominated by Corynespora cassiicola (27\%), followed by Dactylonectria macrodidyma (12\%) and F. oxysporum (13\%) (Fig. 1; Supplementary Table S1).

Of the 69 unique taxa, 26 were present only in corn, 26 were present only in soybean, and 17 were present in both crop species. Taxa unique to corn roots included the potential plant pathogens, Diaporthe longicolla and Drechslera sp., and several species of Trichoderma, Exophiala, and Mortierella. Taxa unique to soybean roots included the soybean pathogen Corynespora cassiicola and several nematophagous taxa, including Arthrobotrys iridis, Metacordyceps chlamydosporia, and Hirsutella rhossiliensis. Of the taxa common to both corn and soybean roots, four had a significantly different abundance between hosts according to the Wilcoxon ranksum test (false discovery rate $[\mathrm{FDR}]$-corrected $P<0.05$ ). Of these, F. oxysporum, Setophoma terrestris, and Periconia macrospinosa

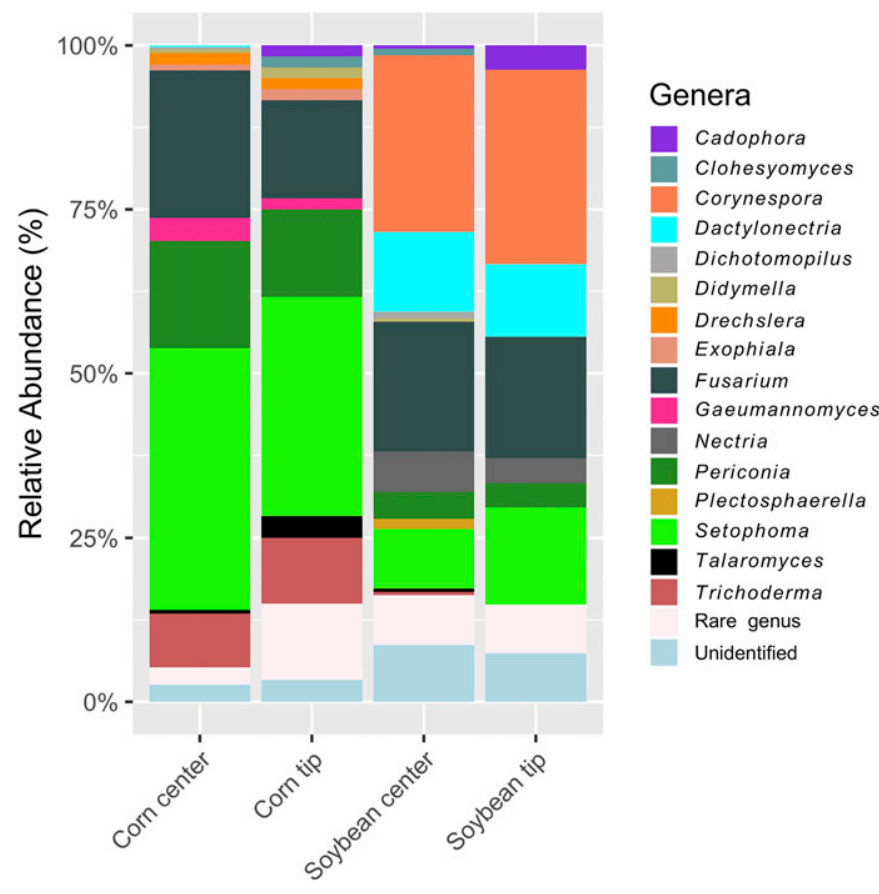

Fig. 1. Community profiles of cultured fungal endophytes from the center or tip of corn and soybean lateral roots. Of 18 lateral roots collected from each plot, 15 were sampled from the center and three were sampled from the tip. Genera that were isolated fewer than three times total are combined in the "rare genus" category. were more abundant in corn roots, and Dactylonectria macrodidyma was more abundant in soybean roots.

Fungal endophytes isolated from the root tips of corn and soybean. Although they were not sampled as intensively as the central portion of the root, endophytic communities isolated from the root tips were similar in taxon composition to the central regions of lateral roots of each respective host (Fig. 1). However, some taxa were only isolated from the root tips of corn and soybean. For example, in corn roots, fungi belonging to the genera Mortierella, Epicoccum, Diaporthe, Paramicrothyrium, Clohesyomyces, and Cadophora were isolated from root tips but not from central root sections (Supplementary Table S1). In soybean, only two taxa, Hirsutella rhossiliensis and Myrothecium verrucaria, were isolated exclusively from root tips (Supplementary Table S1).

Effects of crop host, crop sequence treatment, and SCN density on fungal root endophytic communities. The adonis test showed that fungal endophyte community composition differed by crop host $(P=0.001)$ and by crop sequence within corn $(P=$ $0.056)$ and soybean $(P=0.012)$ (Table 1$)$. Likewise, principal coordinates analysis showed a clear separation of fungal endophyte communities based on crop host and progressive shifts by crop sequence from early to later years of monoculture within each crop host (Fig. 2). In both corn and soybean, fifth-year (C5 and S5) communities mapped close to long-term monoculture (Cc and Ss) communities associated with their respective crops. Corn root

TABLE 1. $R^{2}$ and $P$ values calculated by the adonis test on the Bray-Curtis dissimilarity matrix for crop host and crop sequence effects on the root endophytic fungal communitya

\begin{tabular}{lcc}
\hline Treatment & $R^{2}$ & $P$ value \\
\hline Crop host & 0.24 & $0.001^{*}$ \\
Corn crop sequences & 0.26 & 0.056 \\
Soybean crop sequences & 0.25 & $0.012^{* *}$ \\
All crop sequences & 0.44 & $0.001^{*}$ \\
\hline
\end{tabular}

a Adonis was run with 999 permutations on the models Dissimilarity $\sim$ Block + Host and Dissimilarity $\sim$ Block + Crop Sequence.

b Asterisks indicate significance at $* P<0.01$ and $* * P<0.05$.

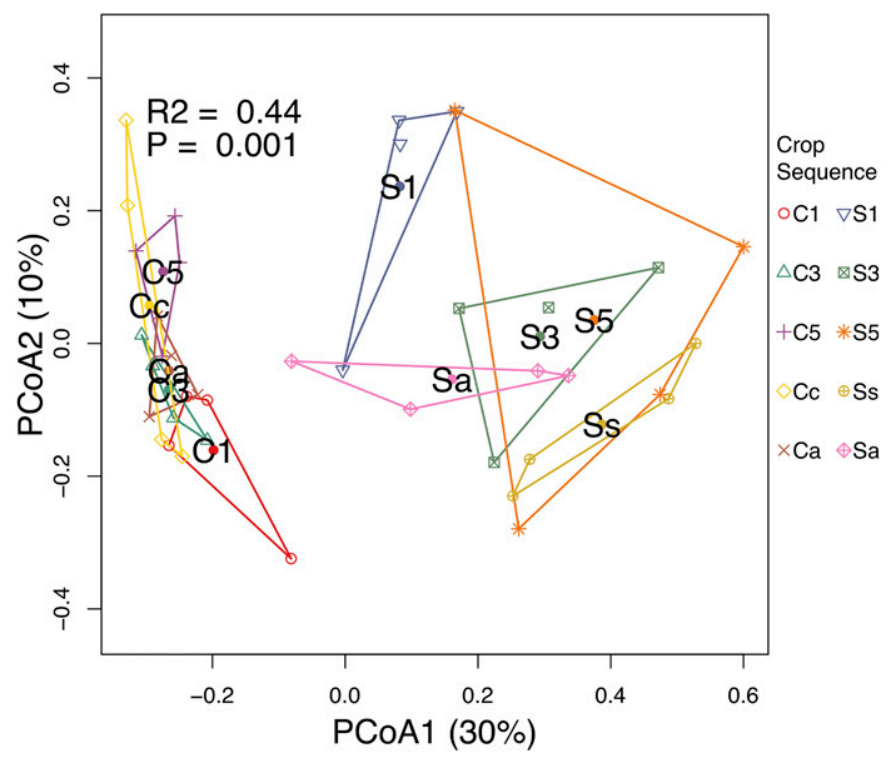

Fig. 2. Principal coordinates analysis (PCoA) of culture-dependent endophyte communities of corn and soybean roots across crop sequences. $R^{2}$ and $P$ values are reported for the Crop Sequence term of the model, Dissimilarity $\sim$ Block + Crop Sequence, determined using adonis. Crop sequences are as follows: C1, $\mathrm{C} 3, \mathrm{C} 5, \mathrm{~S} 1, \mathrm{~S} 3, \mathrm{~S} 5=$ years 1,3 , and 5 of continuous corn or soybean monoculture; $\mathrm{Cc}$ and $\mathrm{Ss}=35$ years of continuous corn or soybean monoculture; and $\mathrm{Ca}$ and $\mathrm{Sa}=$ corn and soybean in annual rotation, respectively. 
endophyte communities were more tightly clustered overall, whereas soybean root endophyte communities shifted more in relation to crop sequence, with communities from annual rotation (Sa) and first-year monoculture (S1) plots mapping closer to corn root endophyte communities (Fig. 2). Although OTU richness did not significantly vary by crop sequence in either crop, corn roots hosted a significantly more diverse fungal community compared with soybean (Table 2).

Only one taxon, Corynespora cassiicola, was found to significantly differ in abundance across soybean crop sequences according to the Kruskal-Wallis test $(P=0.04)$, but this result was nonsignificant after FDR correction (FDR-corrected $P=$ 0.5). Corynespora cassiicola was least abundant in the first year (S1) and most abundant in the long-term soybean monoculture (Ss) plots (Supplementary Table S2). No taxa were found to differ significantly in abundance across corn crop sequences.

SCN density has previously been shown to increase with increasing years of soybean monoculture and to decrease with increasing years of corn monoculture in these plots at our study site (Grabau and Chen 2016a, b) and exhibited a similar trend in our sampling year (Hu et al. 2018) (Supplementary Fig. S1). Within soybean plots, alpha diversity was significantly correlated with SCN density (Table 2). Although no OTUs or taxa in either crop host were found to be significantly correlated with SCN density or with crop yield after FDR correction, one OTU identified as F. solani had a positive correlation with SCN density in soybean before FDR correction (rho $=0.55 ; P=0.01$, FDR-corrected $P=0.76$ ), and one taxon, Setophoma terrestris, was negatively correlated with corn yield before FDR correction (rho $=-0.48 ; P=0.03$, FDR-corrected $P=0.61)$.

Nematicidal activity of fungal culture filtrates in relation to media type, pH, and SCN density. Overall, nematicidal activity was greater in filtrates of fungal cultures grown in SMAT than in MEB (Fig. 3A and B). Despite buffering with ammonium tartrate, the $\mathrm{pH}$ of the SMAT media was substantially altered during growth of the fungal strains, with final values ranging from 3.25 to 9.01 (Fig. 3A). The majority of nematicidal SMAT filtrates were below $\mathrm{pH} 5$ or above $\mathrm{pH} 8$ (Fig. 3A). Many SMAT media controls in the same $\mathrm{pH}$ range as some nematicidal filtrates had equal or greater nematicidal activity, especially below pH 5 (Fig. 3C). In contrast, MEB negative controls only showed significant nematicidal activity above $\mathrm{pH} 9$, which was outside of the observed $\mathrm{pH}$ range of MEB fungal culture filtrates (Fig. 3D). All SMAT filtrates that originally had a $\mathrm{pH}<5$ lost all nematicidal activity when neutralized (Supplementary Fig. S2A). Most SMAT filtrates that originally had a $\mathrm{pH}>8$ retained some or all nematicidal activity when neutralized, but nematicidal activity was often less in neutralized filtrates (Supplementary Fig. S2B).

In the first bioassay trial, 34 isolates in SMAT and 43 isolates in MEB were identified that produced significantly more J2 deaths than negative controls in the same $\mathrm{pH}$ range at any timepoint (Supplementary Tables S3 and S4) according to a nonparametric Dunnett's test (Konietschke et al. 2015). A majority of isolates that killed $>50 \%$ of $\mathrm{J} 2 \mathrm{~s}$ at $72 \mathrm{~h}$ in SMAT culture filtrates in the first trial were members of the genus Fusarium (Table 3). Six Fusarium isolates and one isolate of Epicoccum nigrum produced basic filtrates that retained 90 to $100 \%$ nematicidal activity at $72 \mathrm{~h}$ when neutralized (Table 3). Additional isolates with $>50 \%$ nematicidal activity at $72 \mathrm{~h}$ in SMAT included Dactylonectria macrodidyma, Exophiala equina, Myrothecium verrucaria, and Trichoderma gamsii (Table 3). Hirsutella rhossiliensis and Waitea circinata produced culture filtrates in MEB that resulted in $>25 \% \mathrm{~J} 2$ deaths at $72 \mathrm{~h}$ in the first trial (Table 4).

We repeated these assays a second time for 12 isolates showing high nematicidal activity in the first trial. In the second bioassay trial, none of the MEB filtrates had nematicidal activity significantly greater than media controls. Therefore, data are only displayed for the SMAT filtrates (Table 5). All of the SMAT filtrates in the second trial had significant nematicidal activity comparable to the activity observed for the same isolates in the first trial (Tables 3 and 5). The $\mathrm{pH}$ of nematicidal filtrates was similar for most isolates in the first and second trials, except for the Myrothecium verrucaria isolate, which produced an acidic, rather than a basic, filtrate in the second trial (Tables 3 and 5). Fresh neutralized SMAT filtrates that originally were above $\mathrm{pH} 8$ had approximately the same nematicidal activity when neutralized (Table 5). The Hirsutella rhossiliensis isolate did not produce SCN-toxic filtrates in MEB in the second trial but did produce moderately toxic filtrates in SMAT (Table 5). No significant patterns were identified between the proportion of isolates with nematicidal culture filtrates per plot and crop host, crop sequence, or SCN density.

\section{DISCUSSION}

Corn and soybean host distinct CD endophytic communities. Our first hypothesis, that corn and soybean would host distinct root endophyte communities, was supported by our community-level analyses (Fig. 2; Table 1) and by the isolation frequency of specific taxa from corn and soybean roots (Fig. 1). Interestingly, the CD communities of corn and soybean roots in our study differed from those reported in other culture-based studies. Previous studies of corn root endophytes have found that the community was dominated by the genera Fusarium and Alternaria in Missouri clay soil in a greenhouse experiment (Bokati et al. 2016) and on the Indian subcontinent (Potshangbam et al. 2017) with other commonly reported genera including Acremonium, Aspergillus, Colletotrichum, Mucor, Penicillium, Saccharomyces, Sarocladium, and Trichoderma (Amin 2013; Bokati et al. 2016; Orole and Adejumo 2011; Potshangbam et al. 2017; Russo et al. 2016). While our corn root endophyte community contained many Fusarium isolates, it was dominated by a potential corn pathogen, Setophoma terrestris (Mao et al. 1998), which may also explain a reddish discoloration observed in many of our corn root sections (Lević et al. 2013). The negative correlation between Setophoma terrestris abundance and corn yield, although not significant after FDR correction, nonetheless suggests that this fungus may be implicated in the yield declines observed under continuous corn monoculture (Seifert et al. 2017). Setophoma terrestris has been identified as the primary pathogen in red root rot of corn (Mao et al. 1998) and is in the order Pleosporales, which contains many plant pathogens, including the ubiquitous genus Alternaria (Zhang et al. 2012), suggesting that different pathogens from this order may be more or less prevalent at different sites.

Previous studies of soybean root endophytes have found that Fusarium isolates dominated this community (Russo et al. 2016; Yang et al. 2018), with other commonly reported genera including Alternaria, Aspergillus, Bipolaris, Cadophora, Cladosporium Clonostachys, Colletotrichum, Corynespora, Curvularia, Fusarium, Macrophomina, Mortierella, Mucor, Penicillium, Phaeosphaeria, Phoma, Phomopsis, Rhizoctonia, Rhizopus, Talaromyces, and Trichoderma (Fernandes et al. 2015; Hamayun et al. 2009; Rothen et al. 2017; Russo et al. 2016; Yang et al. 2018). In contrast

TABLE 2. Patterns of root endophyte alpha diversity

\begin{tabular}{lcc}
\hline Host & Mean richness $(\text { S.D. })^{\mathrm{a}}$ & $\mathrm{SCN}(\beta)^{\mathrm{b}}$ \\
\hline Corn & $10.4(2.6)^{* * *}$ & 0.099 \\
Soybean & $7.3(3.0)^{* * *}$ & $0.12^{* *}$ \\
\hline a Mean richness was compared using analysis of variance on the linear model \\
Richness $\sim$ Block + Host. Asterisks indicate significance at $* * * P<0.001$ \\
and $* * P<0.01$.
\end{tabular}

Vol. 110, No. 3, 2020 607 
to these studies, we found that the fungal root endophyte community in soybean was dominated by Corynespora cassiicola. This fungus is known to be pathogenic on soybean roots and leaves without causing significant yield losses (Seaman et al. 1965). The fungus has also been isolated from $\mathrm{SCN}$ cysts but has little parasitic ability on SCN eggs (Chen and Chen 2002).

Many endophyte studies report on communities characterized by both CD and CI methods (Fernandes et al. 2015; Impullitti and Malvick 2013; Yang et al. 2018). Although here we only report on the CD community, we described the CI community in a previous study utilizing the same root systems (Strom et al. 2019a). Some patterns were similar across the two study types. Both methods, for example, showed that Corynespora cassiicola and Setophoma terrestris were strongly associated with soybean and corn roots, respectively, and ordination plots showing the effect of crop sequence on corn and soybean endophyte communities were similar for the two methods (Fig. 2). However, the CI method captured far more fungal diversity, with a total of 221 and 189 genera (Strom et al. 2019a) compared with only 33 and 39 genera from the CD method in corn and soybean roots, respectively. These findings agree with previous reports of fungal endophyte diversity in corn and soybean that have found that CI methods generally capture greater fungal diversity than CD methods (Bokati et al. 2016; Yang et al. 2018). However, one study of soybean stem endophytes found greater diversity using a CD method compared with a CI method (Impullitti and Malvick 2013).

Soybean root endophyte community shaped by crop sequence and the SCN. Although we did not detect many significant differences in the abundance of taxa across crop sequences, the endophyte community as a whole varied by crop sequence, especially for soybean (Fig. 2; Table 1), suggesting that some abiotic or biotic factors associated with crop sequence treatment played a role in shaping the soybean root endophyte community. The positive correlation between SCN density and endophyte alpha diversity in soybean roots (Table 2) suggests that the SCN may play a role. This increase in endophytic fungal alpha diversity could be attributable to the SCN opening up sites on the root through which fungi colonize (Westphal et al. 2014), or SCN juveniles could be transporting fungi attached to their cuticles into the roots (Chen and Dickson 2012).
A J2 mortality in SMAT fungal culture filtrates

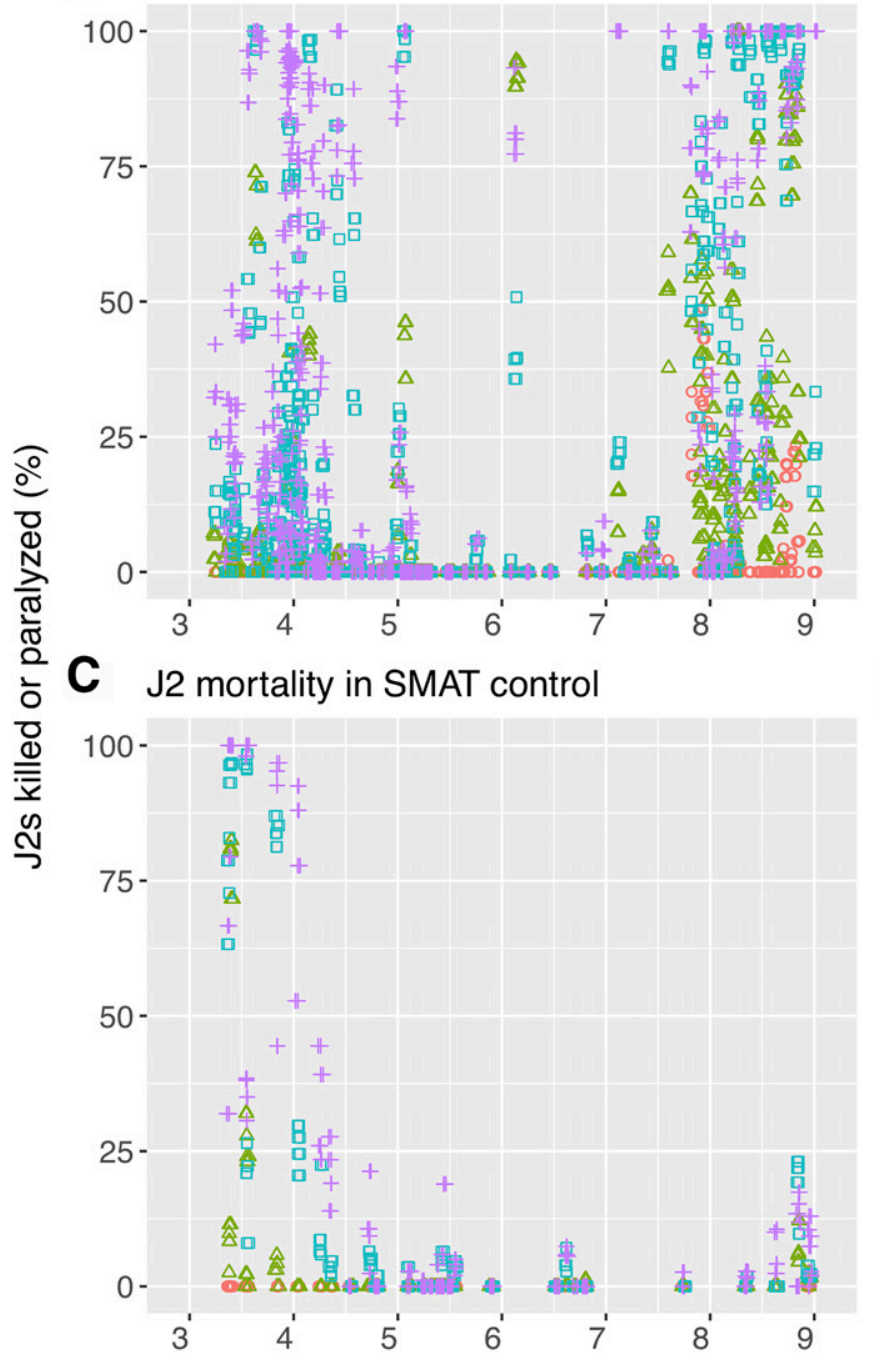

\section{B J2 mortality in MEB fungal culture filtrates}

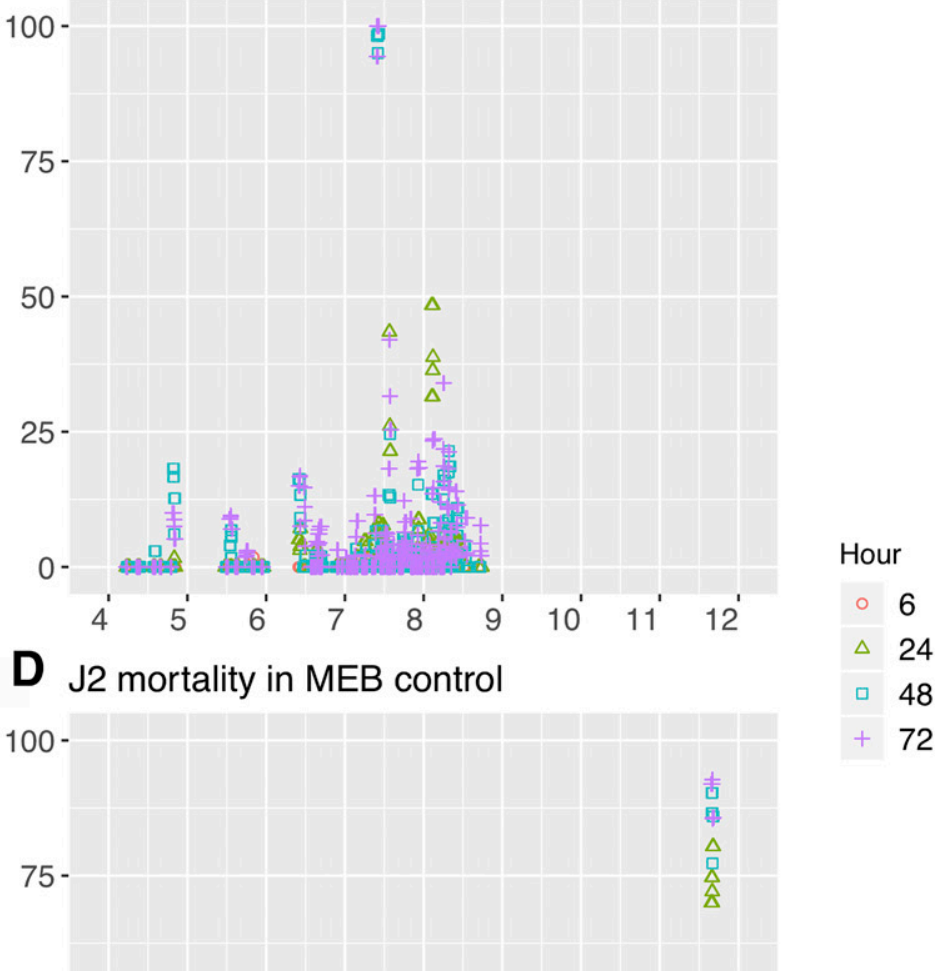

$50-$

$25-$

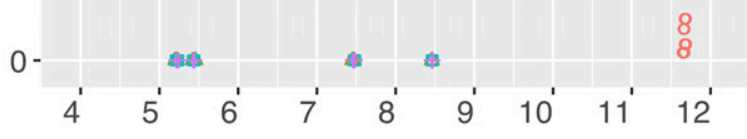

$\mathrm{pH}$

Fig. 3. Percentage of Heterodera glycines second-stage juveniles (J2s) killed or paralyzed in fresh non-neutralized filtrates of fungal cultures and media controls in A, secondary metabolite-inducing media buffered by ammonium tartrate (SMAT) and B, malt extract broth (MEB) and in C, SMAT and D, MEB media controls with no fungal growth across a $\mathrm{pH}$ range. Symbols represent the percentage of J2s killed or paralyzed in individual wells on a 24 -well plate. A jitter effect was used to slightly displace some of the symbols to avoid overlap. 
The root endophyte community of several plant species has been hypothesized to be composed of a subset of the rhizosphere microbial community (Bulgarelli et al. 2013; Edwards et al. 2015; Sasse et al. 2018; Strom et al. 2019a), which may be altered in response to pathogen attack (Lareen et al. 2016). In a greenhouse experiment in which soybean plants were challenged with the SCN, the soybean rhizosphere became enriched in several bacterial taxa with putative roles in SCN suppression (Hussain et al. 2018). This study also showed that the SCN cyst bacterial community was closely related to the soybean root endosphere bacterial community and was initially assembled through the selection of bacterial taxa from the soybean root endosphere. Carris et al. (1986, 1989) hypothesized that soybean root endophytic fungi may grow into SCN cysts attached to the root. It was later shown that several species of fungi, including several species of nematophagous fungi, isolated from SCN cysts can in fact colonize soybean roots endophytically (Stiles and Glawe 1989). A study of fungi using CI approaches at our study site found a similar pattern in which fungal taxa inhabiting SCN cysts showed greater overlap with taxa found in soybean roots compared with corn roots (Strom et al. 2019a). This study builds on these findings by showing that many nematophagous fungi, including Arthrobotrys iridis, a nematode-trapping fungus (Yu et al. 2014), M. chlamydosporia (syn. Pochonia chlamydosporia), a nematode egg parasite (Manzanilla-Lopez et al. 2013), and Hirsutella rhossiliensis, a nematode endoparasite (Wang et al. 2016), can grow endophytically in soybean roots. Collectively, these results suggest that pathogen pressure from the SCN may alter the root endophyte mycobiota of SCN-susceptible soybean.
Fungal endophytes from the root tip. Most culture-based studies do not indicate that the root tip is a common sampling site for fungal endophytes (Potshangbam et al. 2017; Russo et al. 2016; Yang et al. 2018). The root tip is a site of active growth and secretion of mucilage and other exudates (Badri and Vivanco 2009). These secretions attract fungi (Graham et al. 1981), bacteria (Bulgarelli et al. 2013), and nematodes (Curtis 2008), including SCN juveniles (Papademetriou and Bone 1983), resulting in rhizosphere microbial communities distinct from more mature root regions (Kawasaki et al. 2016; Massalha et al. 2017; Sasse et al. 2018). SCN juvenile density has been shown to be highest surrounding soybean root tips (Hu et al. 2017b).

Overall, the fungal communities recovered from the root tip were similar in composition to those in central sections of the root (Fig. 1; Supplementary Table S1), but because roots tips were sampled with less frequency than central portions of the root, we did not quantitatively compare endophyte communities isolated from these two different regions of the root. However, despite five-fold greater sampling of central sections of roots, several fungi of interest for use in biocontrol or nutrient acquisition were only isolated from the root tip sections. For example, the only isolate of Hirsutella rhossiliensis, a potential biocontrol agent of the SCN (Zhang et al. 2008), and the only isolate of Myrothecium verrucaria, which has been developed into a commercial nematicide ( $\mathrm{Li}$ et al. 2015; Valent BioSciences 2010), were isolated only from soybean root tips. Furthermore, the corn root tip hosted the only two isolates of Mortierella, a genus with roles in soil phosphorus solubilization (Osorio and Habte 2014). Some Mortierella isolates have been

TABLE 3. Percentage of second-stage juveniles (J2s) killed or paralyzed in nematicidal filtrates of isolates cultured in secondary metabolite-inducing media buffered with ammonium tartrate (SMAT) ${ }^{\mathrm{a}}$

\begin{tabular}{|c|c|c|c|c|c|c|c|c|c|c|c|}
\hline \multirow[b]{2}{*}{ OTU ID ${ }^{\mathrm{b}}$} & \multirow[b]{2}{*}{ Isolate ID } & \multirow[b]{2}{*}{ Taxonomy } & \multicolumn{6}{|c|}{ Incubation period $(\mathrm{h})^{\mathrm{c}}$} & \multirow[b]{2}{*}{$\begin{array}{l}\text { SMAT } \\
\text { pH }\end{array}$} & \multirow[b]{2}{*}{$\begin{array}{c}\text { Neutralized } \\
\mathrm{pH}\end{array}$} & \multirow[b]{2}{*}{ Host } \\
\hline & & & 6 & 24 & 48 & 72 & $\begin{array}{c}72 \\
\text { (thawed) }\end{array}$ & $\begin{array}{c}72 \\
\text { (neutralized) }\end{array}$ & & & \\
\hline 1 & 205A_c9.1 & Dactylonectria macrodidyma & 0 & 3.7 & $5.3^{*}$ & $7.1^{*}$ & $100 *$ & $49.8^{*}$ & 8.23 & 5.32 & Corn \\
\hline 1 & 308B_c4.1 & Dactylonectria macrodidyma & 0.4 & $8.5^{*}$ & $22.4^{*}$ & $24.8^{*}$ & $87.5^{*}$ & 4.4 & 8.24 & 5.5 & Soybean \\
\hline 36 & 302B_c7.1 & Epicoccum nigrum & 0 & $34.5^{*}$ & $33.8^{*}$ & $18.5^{*}$ & $100 *$ & $98^{*}$ & 8.54 & 7.46 & Soybean \\
\hline 32 & 403A_T17.2 & Exophiala equina & 2 & $77.3^{*}$ & $91.1^{*}$ & $89.8^{*}$ & $100 *$ & $30.1 *$ & 8.78 & 6.31 & Corn \\
\hline 26 & 401B_T17.1 & F. oxysporum & 0 & $24.3^{*}$ & $21.5^{*}$ & $19.9^{*}$ & $100 *$ & 7.1 & 8.47 & 7.83 & Corn \\
\hline 26 & 403A_c5.1 & F. oxysporum & $17.4 *$ & $85.8^{*}$ & $79.7 *$ & $85.3 *$ & $100 *$ & $100 *$ & 8.74 & 5.87 & Corn \\
\hline 26 & 404A_c1.2 & F. oxysporum & 1 & $15.8^{*}$ & $28.6^{*}$ & $21.7 *$ & $95.5^{*}$ & $21^{*}$ & 8.21 & 7.18 & Corn \\
\hline 26 & $302 \mathrm{~B} \_\mathrm{c} 13.1$ & F. oxysporum & 0 & $18.1^{*}$ & $22.9 *$ & $30.3 *$ & $100^{*}$ & $91.6^{*}$ & 8.02 & 6.84 & Soybean \\
\hline 3 & 110A_c3.1 & F. oxysporum & 0.4 & $100^{*}$ & $95.6^{*}$ & $100 *$ & $100 *$ & $100^{*}$ & 8.27 & 5.71 & Corn \\
\hline 3 & 207A_c10.1 & F. oxysporum & 0 & $26.4 *$ & $97.9^{*}$ & $100 *$ & $86.9^{*}$ & $13.3 *$ & 8.59 & 7.38 & Corn \\
\hline 12 & 407B_c13.1 & Fusarium sp. & 0 & $100 *$ & $57.6^{*}$ & $70.7^{*}$ & $100 *$ & $100^{*}$ & 8.26 & 6.24 & Soybean \\
\hline 102 & $111 \mathrm{~A}^{-} \mathrm{T} 4.1$ & Myrothecium verrucaria & 0 & $75.2 *$ & $87.1 *$ & $82.5^{*}$ & $100 *$ & $26.4^{*}$ & 8.46 & 5.98 & Soybean \\
\hline 74 & 410B_T17.1 & Trichoderma gamsii & 0 & $92.4 *$ & $41.4^{*}$ & $82.9 *$ & NA & NA & 6.14 & NA & Corn \\
\hline \multicolumn{12}{|l|}{$\begin{array}{l}\text { Negative } \\
\text { controls }\end{array}$} \\
\hline \multicolumn{12}{|c|}{ SMAT $(\mathrm{pH})$} \\
\hline $3-4$ & & & 0 & 78.9 & 95.7 & 100 & 100 & NA & 3.4 & & \\
\hline $4-5$ & & & 0 & 0 & 25.6 & 77.8 & 77.8 & NA & 4.04 & & \\
\hline $5-6$ & & & 0 & 0 & 0.9 & 1.4 & 1.4 & 1.4 & 5.05 & & \\
\hline $6-7$ & & & 0 & 0.6 & 0 & 0 & 0 & 0 & 6.8 & & \\
\hline $7-8$ & & & 0 & 0 & 0 & 0.7 & 0 & 0 & 7.75 & & \\
\hline $8-9$ & & & 0 & 2 & 2 & 1.7 & 10 & NA & 8.95 & & \\
\hline Water & & & 0 & 0 & 0 & 0 & 0 & 0 & & & \\
\hline
\end{tabular}

a Filtrates that killed or paralyzed a minimum of $50 \%$ of $\mathrm{J} 2 \mathrm{~s}$ at $72 \mathrm{~h}$ are included in this table. SMAT culture filtrates with a pH $<5$ or $>8$ were thawed and neutralized such that the neutralized $\mathrm{pH}$ was between $\mathrm{pH} 5$ and 8 . These thawed and neutralized filtrates were retested at the 72-h timepoint.

$\mathrm{b}$ OTU = operational taxonomic unit and ID = identifier.

c Asterisks indicate that the percentage of J2s killed or paralyzed was greater than in media controls in the same $\mathrm{pH}$ range according to a nonparametric Dunnett's test (false discovery rate-corrected $P<0.05$ ). NA = not applicable. 
shown to degrade toxic compounds in the soil, increase soil organic matter, and promote growth in corn (Li et al. 2018). It is possible that such isolates could ultimately be developed into biofertilizers that could reduce reliance on inorganic sources of phosphorus and improve crop yields (Li et al. 2018). Recovery of endophytes from plant tissues is highly variable and influenced by many factors, and more intensive sampling is required to assess the distribution of these fungi spatially within roots. Nonetheless, these observations suggest that root tips may harbor unique taxa and should be sampled along with other root sections in bioprospecting studies seeking to isolate fungi with potential biocontrol and biofertilizer applications.

Nematicidal activity of fungal culture filtrates in relation to media type, $\mathbf{p H}$, and SCN density. We hypothesized that more endophytes isolated from long-term soybean monoculture plots would produce nematicidal culture filtrates. Although this hypothesis was not supported, we did identify a number of fungal isolates that produced culture filtrates with nematicidal activity against the SCN. Previous studies testing culture filtrates of fungi for activity against the SCN have primarily relied on rich media, like potato dextrose broth (PDB) (Juba et al. 2004) or MEB (Chen et al. 2000b) for induction of secondary metabolite production. In a pilot study, we tested PDB for the induction of nematicidal compound production by fungi but found that none of the PDB filtrates had any nematicidal activity against the SCN. Here, we show that a synthetic medium (SMAT) induced nematicidal compound production in a greater number of fungal isolates than MEB and that nematicidal activity was generally greater in this synthetic media than in MEB (Fig. 3). However, very slow-growing isolates, like Hirsutella rhossiliensis, had limited growth in SMAT but had robust growth and produced nematicidal compounds in MEB in the first trial. These results suggest that a best practice for screening fungi for toxic compound production may be to utilize two contrasting types of media, one to induce secondary

TABLE 4. Percentage of second-stage juveniles (J2s) killed or paralyzed in nematicidal filtrates of isolates cultured in malt extract broth (MEB) ${ }^{\mathrm{a}}$

\begin{tabular}{|c|c|c|c|c|c|c|c|c|}
\hline \multirow[b]{2}{*}{ OTU ID $^{b}$} & \multirow[b]{2}{*}{ Isolate ID } & \multirow[b]{2}{*}{ Taxonomy } & \multicolumn{4}{|c|}{ Incubation period $(\mathrm{h})^{\mathrm{c}}$} & \multirow[b]{2}{*}{ MEB pH } & \multirow[b]{2}{*}{ Host } \\
\hline & & & 6 & 24 & 48 & 72 & & \\
\hline 3 & 207A_c10.1 & Fusarium oxysporum & 0 & $5 *$ & $97.5^{*}$ & $98.6^{*}$ & 7.42 & Corn \\
\hline 71 & 206A_T18.1 & Hirsutella rhossiliensis & 0 & $23.2 *$ & $16^{*}$ & $29.3 *$ & 7.57 & Soybean \\
\hline 49 & 212A_c4.1 & Waitea circinata & 0 & $17.5^{*}$ & $16.2 *$ & $31.5^{*}$ & 7.75 & Corn \\
\hline \multicolumn{9}{|c|}{ Negative controls } \\
\hline MEB & & & 0 & 0 & 0.5 & 0 & 5.21 & \\
\hline Water & & & 0 & 0 & 0 & 0 & & \\
\hline
\end{tabular}

a Only filtrates that killed or paralyzed a minimum of $25 \%$ of $\mathrm{J} 2 \mathrm{~s}$ at $72 \mathrm{~h}$ are included in this table.

b OTU = operational taxonomic unit and ID = identifier.

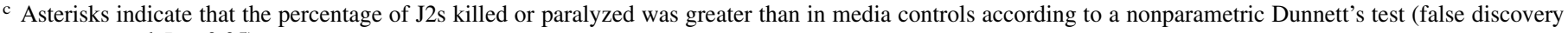
rate-corrected $P<0.05)$.

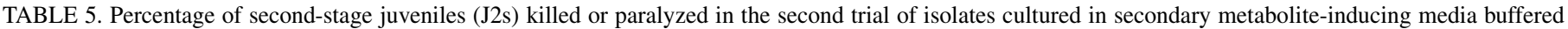
with ammonium tartrate (SMAT) ${ }^{\mathrm{a}}$

\begin{tabular}{|c|c|c|c|c|c|c|c|c|}
\hline \multirow[b]{2}{*}{ OTU ID ${ }^{b}$} & \multirow[b]{2}{*}{ Isolate ID } & \multirow[b]{2}{*}{ Taxonomy } & \multicolumn{4}{|c|}{ Incubation period $(h)^{c}$} & \multirow[b]{2}{*}{$\mathrm{pH}$} & \multirow[b]{2}{*}{ Host } \\
\hline & & & 6 & 24 & 48 & 72 & & \\
\hline \multicolumn{9}{|c|}{ Original $\mathrm{pH}$ filtrate } \\
\hline 1 & 305A_c11.1 & Dactylonectria macrodidyma & 0 & $5.1^{*}$ & $97.3 *$ & $100 *$ & 7.95 & Soybean \\
\hline 36 & 302B_c7.1 & Epicoccum nigrum & 0 & $13.1 *$ & $21.6^{*}$ & $100 *$ & 7.12 & Soybean \\
\hline 32 & 403A_T17.2 & Exophiala equina & 0 & $22.4^{*}$ & $76.4^{*}$ & $100^{*}$ & 7.91 & Corn \\
\hline 18 & 207A_c7.2 & Fusarium acuminatum & 0 & $22.4^{*}$ & $98.3^{*}$ & $100^{*}$ & 8.55 & Corn \\
\hline 44 & 412B_c13.1 & F. dimerum & 2.3 & $33.1 *$ & $100 *$ & $100 *$ & 8.7 & Soybean \\
\hline 3 & 207A_c10.1 & F. oxysporum & 2.8 & $25.9 *$ & $97.3 *$ & $100 *$ & 8.85 & Corn \\
\hline 8 & 110A_c18.2 & F. oxysporum & 0 & $15.3 *$ & $94.5 *$ & $100^{*}$ & 8.38 & Corn \\
\hline 78 & 206A_T16.1 & F. solani & 0 & $7.0^{*}$ & $23.2 *$ & $100^{*}$ & 9.01 & Soybean \\
\hline 12 & 407B_c13.1 & Fusarium sp. & 0 & $8.1^{*}$ & $98.6 *$ & $100^{*}$ & 8.68 & Soybean \\
\hline 71 & 206A_T18.1 & Hirsutella rhossiliensis & 0 & 0.0 & $26.7 *$ & $21.4^{*}$ & 5.01 & Soybean \\
\hline 102 & 111A_T4.1 & Myrothecium verrucaria & 0 & $14.6^{*}$ & $10.3^{*}$ & $88.3^{*}$ & 5.00 & Soybean \\
\hline 74 & 410B_T17.1 & Trichoderma gamsii & 0 & $42.9 *$ & $98.4^{*}$ & $100 *$ & 5.07 & Corn \\
\hline \multicolumn{9}{|c|}{ Neutralized filtrate } \\
\hline 18 & 207A_c7.2 & F. acuminatum & 0 & $19.6^{*}$ & $46.8 *$ & $100 *$ & 7.93 & Corn \\
\hline 44 & 412B_c13.1 & F. dimerum & 0 & $32.5^{*}$ & $98.7 *$ & $100 *$ & 7.97 & Soybean \\
\hline 3 & 207A_c10.1 & F. oxysporum & 0 & $34.2 *$ & $46 *$ & $100^{*}$ & 7.32 & Corn \\
\hline 8 & 110A_c18.2 & F. oxysporum & 0 & $32.4^{*}$ & $100 *$ & $100 *$ & 7.85 & Corn \\
\hline 78 & 206A_T16.1 & F. solani & 0 & $24.9 *$ & $14.6 *$ & $100^{*}$ & 7.83 & Soybean \\
\hline 12 & 407B_c13.1 & Fusarium sp. & 0 & $13.0 *$ & $23.7 *$ & $100^{*}$ & 7.65 & Soybean \\
\hline \multicolumn{9}{|c|}{ Negative controls } \\
\hline \multicolumn{9}{|c|}{ SMAT (pH) } \\
\hline $5-6$ & & & 0 & 0 & 0 & 0 & 5.51 & \\
\hline $6-7$ & & & 0 & 0 & 0 & 0 & 6.70 & \\
\hline $7-8$ & & & 0 & 0 & 0 & 0.7 & 7.75 & \\
\hline $8-9$ & & & 0 & 0 & 0 & 6.8 & 8.64 & \\
\hline Water & & & 0 & 0 & 0 & 0 & 6 & \\
\hline
\end{tabular}

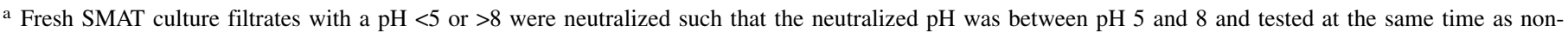
neutralized filtrates.

b OTU = operational taxonomic unit and ID = identifier.

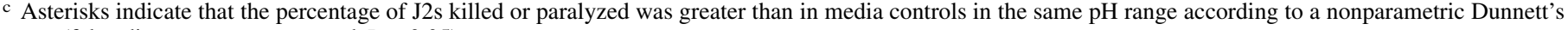
test (false discovery rate-corrected $P<0.05$ ). 
metabolite production in fast-growing isolates and one to encourage growth of slow-growing toxin-producing isolates.

Our research also points to the need to investigate the effect of $\mathrm{pH}$ on nematicidal activity of culture filtrates, given that the $\mathrm{pH}$ of SMAT was a strong determinant of $\mathrm{J} 2$ deaths. Many species of nematophagous fungi are known to produce organic acids with nematicidal activity (Degenkolb and Vilcinskas 2016a). For example, the nematode-trapping fungus Arthrobotrys and nematode egg-parasitic fungus Purpureocillium lilacinum have been shown to produce nematicidal amounts of linoleic acid (Anke et al. 1995; Park et al. 2004). Furthermore, Purpureocillium lilacinum and a non-nematophagous fungus, Trichoderma longibrachiatum, have been shown to produce acetic acid, which was nematicidal principally in its nondissociated form below pH 5 (Favre-Bonvin et al. 1991). However, in our study, while it is possible that SMAT culture filtrates with a $\mathrm{pH}<5$ contained nematicidal compounds that were active only at an acidic $\mathrm{pH}$, it was impossible to separate their effects from those of the acidic media.

Previous studies have shown that secondary metabolite production by fungi increases in acidic media (Calvo et al. 2002; Chen et al. 2000b; Cotty 1988; Gardiner et al. 2009). However, we found that most SMAT filtrates that killed a significant percentage of J2s were originally in a basic $\mathrm{pH}$ range. Several of these filtrates killed $100 \%$ of $\mathrm{J} 2 \mathrm{~s}$ at $72 \mathrm{~h}$, even when neutralized, suggesting that $\mathrm{pH}$ was not a significant factor in their activity. These filtrates, as well as those that had nematicidal activity in a $\mathrm{pH}$ range of 5 to 8 , may prove to be sources of new nematicidal compounds active against the $\mathrm{SCN}$, and the fungi that produced them should be investigated for their biocontrol potential in planta.

Prospects for biocontrol of the $\mathrm{SCN}$ with fungal isolates and culture filtrates. Several isolates produced culture filtrates that exhibited significant activity against the SCN (Tables 3 and 5). However, the ability of these isolates to be developed into biocontrol agents depends on many factors. One factor is the pathogenicity of an isolate on its host plant. Of the isolates that produced culture filtrates exhibiting high nematicidal activity, members of the genera Dactylonectria, Epicoccum, Fusarium, and Myrothecium are all potential plant pathogens (Chen et al. 2016b; Mahadevakumar et al. 2014; Malapi-Wight et al. 2015; Wilman et al. 2014). Various formae speciales of the $F$. oxysporum species complex and the $F$. solani species complex are pathogenic on a broad range of host plants, including soybean (Coleman 2016; Cruz Jimenez 2017). Other strains of $F$. oxysporum and $F$. solani, however, are nonpathogenic (Fravel et al. 2003; Siddiqui and Shaukat 2003). Given the difficulty in distinguishing formae speciales using ITS sequencing alone (O'Donnell et al. 2015), tests for the pathogenicity of Fusarium species and other potentially pathogenic isolates on soybean and corn should be conducted before considering them as candidates for biocontrol.

It is possible, however, to develop chemical nematicides from isolates that are pathogenic on plants, provided no living fungal inoculum is present. Such a nonliving product, marketed as DiTerra, has been developed from the plant pathogen, Myrothecium verrucaria (Wilson and Jackson 2013), and the culture filtrates of the only isolate of Myrothecium verrucaria in our study also showed high nematicidal activity against the SCN. Plant pathogenic Fusarium or Dactylonectria isolates with nematicidal culture filtrates could potentially be developed into similar products. Some research suggests that nematicidal endophytes can produce toxins at a level that is nematicidal in plant roots (Bacetty et al. 2009), but for the most part, this question is unresolved (Schouten 2016). Fungal secondary metabolites have been shown to have nematicidal activity at similar concentrations in previous in vitro and in vivo assays (Mayer et al. 1999), suggesting that direct application of fungal culture filtrates may be effective in agricultural settings.

A second consideration for biocontrol agents is that they should not be dangerous to humans or other organisms, aside from their target organism. Isolates of several Fusarium spp., including those in the $F$. solani, F. oxysporum, and $F$. dimerum species complexes can cause diseases of the cornea (Hassan et al. 2016) and may pose a greater threat to immunocompromised individuals (Zhang et al. 2006). Epicoccum nigrum, one isolate of which produced culture filtrates with high nematicidal activity, is also implicated in some human respiratory diseases, including allergic asthma (Summerbell 2001). Likewise, Exophiala equina may opportunistically infect human skin (Najafzadeh et al. 2013). Although many strains of these fungi may not pose a threat, fungi for which human or animal pathogenicity is a concern should not be considered for biocontrol.

Of the isolates that produced culture filtrates with high nematicidal activity, those that have previously been identified as potential biocontrol agents of nematodes or other organisms may hold the greatest potential. Trichoderma gamsii, one isolate of which showed high nematicidal activity in this study, is a fastgrowing nonpathogenic endophyte that can antagonize a variety of fungal pathogens as well as promote plant growth in corn, soybean, wheat, and lentil (Chen et al. 2016a; Rinu et al. 2014). While to our knowledge, Trichoderma gamsii has not been tested for the biocontrol of nematodes, related Trichoderma species, such as Trichoderma virens and Trichoderma harzianum, have shown some potential in controlling populations of the root-knot nematode (Meloidogyne incognita and Meloidogyne javanica) in greenhouse studies, mostly through parasitism of nematode eggs (Mascarin et al. 2012; Massoud et al. 2000; Sahebani and Hadavi 2008; Sharon et al. 2007). Our isolate of Trichoderma gamsii has the potential to be a novel biocontrol agent of the SCN.

Hirsutella rhossiliensis may also hold potential as a biocontrol agent of the SCN. Although our Hirsutella rhossiliensis isolate showed lower nematicidal activity compared with other nematicidal isolates, this could be attributable to the synthetic media used. As a near-obligate parasite of nematodes, it has several beneficial traits for biocontrol, such as better growth in the presence of high population levels of the SCN (Chen and Liu 2005; Zhang et al. 2008) and a lower likelihood to affect nontarget organisms. However, it may be difficult to mass produce, given its slow growth rate in most synthetic media types (Liu and Chen 2002).

Conclusions. Here, we show that roots of the corn and soybean varieties planted at this study site host distinct communities of root endophytic fungi and that both crop sequence and the SCN play a role in shaping these communities. Several species of nematophagous fungi were isolated from the soybean root, suggesting that this agroecosystem compartment hosts fungi with potential roles in parasitizing the SCN. Isolates from both plant hosts produced compounds toxic to the $\mathrm{SCN}$ in vitro and may hold promise for the biocontrol of the SCN. Future research should focus on characterizing metabolites produced by these fungi and on testing their ability to control the SCN in the greenhouse and field. Sustainable approaches to control the SCN are needed, and endophytes may offer one part of the solution.

\section{ACKNOWLEDGMENTS}

We thank Wayne Gottschalk and Jeff Bauman for help in collecting root samples and Cathryn Johnson for providing SCN cysts for bioassays; Yen Vuong for assistance in plating root sections; and Erica Miller for assistance in culturing endophytes and collecting culture filtrates.

\section{LITERATURE CITED}

Altschul, S. F., Gish, W., Miller, W., Myers, E. W., and Lipman, D. J. 1990. Basic local alignment search tool. J. Mol. Biol. 215:403-410.

Alvin, A., Miller, K. I., and Neilan, B. A. 2014. Exploring the potential of endophytes from medicinal plants as sources of antimycobacterial compounds. Microbiol. Res. 169:483-495.

Amin, N. 2013. Diversity of endophytic fungi from root of maize var. pulut (waxy corn local variety of South Sulawesi, Indonesia). Int. J. Curr. Microbiol. Appl. Sci. 2:148-154. 
Anderson, M. J. 2001. A new method for non-parametric multivariate analysis of variance. Austral Ecol. 26:32-46.

Anke, H., Stadler, M., Mayer, A., and Sterner, O. 1995. Secondary metabolites with nematicidal and antimicrobial activity from nematophagous fungi and Ascomycetes. Can. J. Bot. 73(suppl 1):932-939.

Bacetty, A. A., Snook, M. E., Glenn, A. E., Noe, J. P., Nagabhyru, P., and Bacon, C. W. 2009. Chemotaxis disruption in Pratylenchus scribneri by tall fescue root extracts and alkaloids. J. Chem. Ecol. 35:844-850.

Badri, D. V., and Vivanco, J. M. 2009. Regulation and function of root exudates. Plant Cell Environ. 32:666-681.

Bajaj, R., Hu, W., Huang, Y., Chen, S., Prasad, R., Varma, A., and Bushley, K. E. 2015. The beneficial root endophyte Piriformospora indica reduces egg density of the soybean cyst nematode. Biol. Control 90:193-199.

Bardgett, R. D., and Wardle, D. A. 2010. Aboveground-Belowground Linkages: Biotic Interactions, Ecosystem Processes, and Global Change. Oxford University Press, Oxford, UK.

Bever, J. D. 1994. Feedback between plants and their soil communities in an old field community. Ecology 75:1965-1977.

Bokati, D., Herrera, J., and Poudel, R. 2016. Soil influences colonization of root-associated fungal endophyte communities of maize, wheat, and their progenitors. J. Mycol. 2016:1-9.

Bulgarelli, D., Schlaeppi, K., Spaepen, S., Ver Loren van Themaat, E., and Schulze-Lefert, P. 2013. Structure and functions of the bacterial microbiota of plants. Annu. Rev. Plant Biol. 64:807-838.

Byun, T. J., and Haarith, D. 2018. dhtrim.py - Python program to trim sanger sequences based on quality. GitHub Repos. https://github.com/deepak-plpa/ Fusarium-dominated-SCN-Cyst-Mycobiome/blob/master/dhtrim.py

Calvo, A. M., Wilson, R. A., Bok, J. W., and Keller, N. P. 2002. Relationship between secondary metabolism and fungal development. Microbiol. Mol. Biol. Rev. 66:447-459.

Caporaso, J. G., Kuczynski, J., Stombaugh, J., Bittinger, K., Bushman, F. D., Costello, E. K., et al. 2010. QIIME allows analysis of high-throughput community sequencing data. Nat. Publ. Gr. 7:335-336.

Carris, L. M., Glawe, D. A., and Gray, L. E. 1986. Isolation of the soybean pathogens Corynespora cassiicola and Phialophora gregata from cysts of Heterodera glycines in Illinois. Mycologia 78:503-506.

Carris, L. M., Glawe, D. A., Smyth, C. A., and Edwards, D. I. 1989. Fungi associated with populations of Heterodera glycines in two Illinois soybean fields. Mycologia 81:66-75.

Chen, F., and Chen, S. 2002. Mycofloras in cysts, females, and eggs of the soybean cyst nematode in Minnesota. Appl. Soil Ecol. 19:35-50.

Chen, J. L., Sun, S. Z., Miao, C. P., Wu, K., Chen, Y. W., Xu, L. H., et al. 2016a. Endophytic Trichoderma gamsii YIM PH30019: A promising biocontrol agent with hyperosmolar, mycoparasitism, and antagonistic activities of induced volatile organic compounds on root-rot pathogenic fungi of Panax notoginseng. J. Ginseng Res. 40:315-324.

Chen, S. 2004. Management with biological methods. Pages 207-242 in: Biology and Management of the Soybean Cyst Nematode. D. P. Schmitt, J. A. Wrather, and R. D. Riggs, eds. Walsworth Publishing Company, Marceline, MO.

Chen, S. 2011. Soybean Cyst Nematode Management Guide. University of Minnesota Extension, St. Paul.

Chen, S., Dickson, D., and Mitchell, D. 2000b. Viability of Heterodera glycines exposed to fungal filtrates. J. Nematol. 32:190-197.

Chen, S., and Dickson, D. W. 2012. Biological control of plant-parasitic nematodes. Pages 761-811 in: Practical Plant Nematology. R. H. Manzanilla-López and N. Marbán-Mendoza, eds. Colegio de Postgraduados and Mundi-Prensa, Biblioteca Básica de Agricultura, Guadalajara, Jalisco, Mexico.

Chen, S., and Liu, X. 2005. Control of the soybean cyst nematode by the fungi Hirsutella rhossiliensis and Hirsutella minnesotensis in greenhouse studies. Biol. Control 32:208-219.

Chen, S., Liu, X. Z., and Chen, F. J. 2000a. Hirsutella minnesotensis sp. nov., a new pathogen of the soybean cyst nematode. Mycologia 92:819-824.

Chen, S. Y., and Dickson, D. W. 2000. A technique for determining live second-stage juveniles of Heterodera glycines. J. Nematol. 32:117-121.

Chen, Y., Ran, S., Dai, D., Wang, Y., Hyde, K., Wu, Y., et al. 2016b. Mycosphere essays 2. Myrothecium. Mycosphere. 7:64-80.

Coleman, J. J. 2016. The Fusarium solani species complex: Ubiquitous pathogens of agricultural importance. Mol. Plant Pathol. 17:146-158.

Compant, S., Reiter, B., Sessitsch, A., Nowak, J., Clément, C., and Barka, E. A. 2005. Endophytic colonization of Vitis vinifera by plant growthpromoting bacterium Burkholderia sp. strain PsJN. Appl. Environ. Microbiol. 71:1685-1693

Cotty, P. J. 1988. Aflatoxin and sclerotial production by Aspergillus flavus: Influence of $\mathrm{pH}$. Phytopathology 78:1250-1253.

Crookston, R. K., Kurle, J. E., Copeland, P. J., Ford, J. H., and Lueschen, W. E. 1991. Rotational cropping sequence affects yield of corn and soybean. Agron. J. 83:108-113.
Cruz Jimenez, D. R. 2017. Soybean root rot caused by Fusarium oxysporum and Fusarium graminearum: Interactions with biotic and abiotic factors. Ph.D. dissertation, Iowa State University, Ames.

Curtis, R. H. C. 2008. Plant-nematode interactions: Environmental signals detected by the nematode's chemosensory organs control changes in the surface cuticle and behavior. Parasite 15:310-316.

Daneshkhah, R., Cabello, S., Rozanska, E., Sobczak, M., Grundler, F. M. W., Wieczorek, K., et al. 2013. Piriformospora indica antagonizes cyst nematode infection and development in Arabidopsis roots. J. Exp. Bot. 64: 3763-3774.

Degenkolb, T., and Vilcinskas, A. 2016a. Metabolites from nematophagous fungi and nematicidal natural products from fungi as alternatives for biological control. Part I: Metabolites from nematophagous ascomycetes. Appl. Microbiol. Biotechnol. 100:3799-3812.

Degenkolb, T., and Vilcinskas, A. 2016b. Metabolites from nematophagous fungi and nematicidal natural products from fungi as alternatives for biological control. Part II: Metabolites from nematophagous basidiomycetes and non-nematophagous fungi. Appl. Microbiol. Biotechnol. 100: 3813-3824.

Domka, A. M., Rozpaądek, P., and Turnau, K. 2019. Are fungal endophytes merely mycorrhizal copycats? The role of fungal endophytes in the adaptation of plants to metal toxicity. Front. Microbiol. 10:371.

Edgar, R. C. 2010. Search and clustering orders of magnitude faster than BLAST. Bioinformatics 26:2460-2461.

Edwards, J., Johnson, C., Santos-Medellín, C., Lurie, E., Podishetty, N. K., Bhatnagar, S., et al. 2015. Structure, variation, and assembly of the rootassociated microbiomes of rice. Proc. Natl. Acad. Sci. 112:E911-E920.

Favre-Bonvin, J., Ponchet, M., Djian, C., Arpin, N., and Pijarowski, L. 1991. Acetic acid: A selective nematicidal metabolite from culture filtrates of Paecilomyces lilacinus (Thom) Samson and Trichoderma longibrachiatum Rifai. Nematologica 37:101-112.

Fernandes, E. G., Pereira, O. L., da Silva, C. C., Bento, C. B. P., and de Queiroz, M. V. 2015. Diversity of endophytic fungi in Glycine max. Microbiol. Res. 181:84-92.

Franken, P. 2012. The plant strengthening root endophyte Piriformospora indica: Potential application and the biology behind. Appl. Microbiol. Biotechnol. 96:1455-1464.

Fravel, D., Olivain, C., and Alabouvette, C. 2003. Fusarium oxysporum and its biocontrol. New Phytol. 157:493-502.

Gardiner, D. M., Osborne, S., Kazan, K., and Manners, J. M. 2009. Low pH regulates the production of deoxynivalenol by Fusarium graminearum. Microbiology 155:3149-3156.

Grabau, Z. J., and Chen, S. 2016a. Determining the role of plant-parasitic nematodes in the corn-soybean crop rotation yield effect using nematicide application: II. Soybean. Agron. J. 108:1168-1179.

Grabau, Z. J., and Chen, S. 2016b. Determining the role of plant-parasitic nematodes in the corn-soybean crop rotation yield effect using nematicide application: I. Corn. Agron. J. 108:782-793.

Graham, J. H., Leonard, R. T., and Menge, J. A. 1981. Membrane-mediated decrease in root exudation responsible for phosphorus inhibition of vesicular-arbuscular mycorrhiza formation. Plant Physiol. 68:548-552.

Hall, T. A. 1999. BioEdit: A user-friendly biological sequence alignment editor and analysis program for Windows 95/98/NT. Nucleic Acids Symp. Ser. 41:95-98.

Hallmann, J., and Sikora, R. A. 1994. Occurrence of plant parasitic nematodes and non-pathogenic species of Fusarium in tomato plants in Kenya and their role as mutualistic synergists for biological control of root-knot nematodes. Int. J. Pest Manage. 40:321-325.

Hallmann, J., and Sikora, R. A. 1996. Toxicity of fungal endophyte secondary metabolites to plant parasitic nematodes and soil-borne plant pathogenic fungi. Eur. J. Plant Pathol. 102:155-162.

Hamayun, M., Afzal Khan, S., Ahmad, N., Tang, D. S., Kang, S. M., Na, C. I., et al. 2009. Cladosporium sphaerospermum as a new plant growthpromoting endophyte from the roots of Glycine $\max (\mathrm{L}$.$) . Merr. World J.$ Microbiol. Biotechnol. 25:627-632.

Hardoim, P. R., van Overbeek, L. S., Berg, G., Pirttilä, A. M., Compant, S., Campisano, A., et al. 2015. The hidden world within plants: Ecological and evolutionary considerations for defining functioning of microbial endophytes. Microbiol. Mol. Biol. Rev. 79:293-320.

Hassan, A. S., Al-Hatmi, A. M. S., Shobana, C. S., Van Diepeningen, A. D., Kredics, L., Vágvölgyi, C., et al. 2016. Antifungal susceptibility and phylogeny of opportunistic members of the genus Fusarium causing human keratomycosis in South India. Med. Mycol. 54:287-294.

Hu, W., Samac, D. A., Liu, X., and Chen, S. 2017a. Microbial communities in the cysts of soybean cyst nematode affected by tillage and biocide in a suppressive soil. Appl. Soil Ecol. 119:396-406.

Hu, W., Strom, N., Haarith, D., Chen, S., and Bushley, K. E. 2018. Mycobiome of cysts of the soybean cyst nematode under long term crop rotation. Front. Microbiol. 9:386. 
Hu, Y., You, J., Li, C., Williamson, V. M., and Wang, C. 2017b. Ethylene response pathway modulates attractiveness of plant roots to soybean cyst nematode Heterodera glycines. Sci. Rep. 7:1-13.

Hussain, M., Hamid, M. I., Tian, J., Hu, J., Zhang, X., Chen, J., et al. 2018. Bacterial community assemblages in the rhizosphere soil, root endosphere and cyst of soybean cyst nematode-suppressive soil challenged with nematodes. FEMS Microbiol. Ecol. 94:1-11.

Impullitti, A. E., and Malvick, D. K. 2013. Fungal endophyte diversity in soybean. J. Appl. Microbiol. 114:1500-1506.

Inagaki, H., and Tsutsumi, M. 1971. Survival of the soybean cyst nematode, Heterodera glycines Ichinoehe (Tylenchida:Heteroderidae) under certain storing conditions. Appl. Entomol. Zool. 6:156-162.

Juba, J., Meyer, S., Humber, R., Liu, X. Z., Nitao, J., and Huettel, R. 2004. Activity of fungal culture filtrates against soybean cyst nematode and rootknot nematode egg hatch and juvenile motility. Nematology 6:23-32.

Kawasaki, A., Donn, S., Ryan, P. R., Mathesius, U., Devilla, R., Jones, A., et al. 2016. Microbiome and exudates of the root and rhizosphere of $\mathrm{Bra}$ chypodium distachyon, a model for wheat. PLoS One 11:e0164533.

Kerry, B. R. 2000. Rhizosphere interactions and the exploitation of microbial agents for the biological control of plant-parasitic nematodes. Annu. Rev. Microbiol. 38:423-441.

Khan, A. L., Hamayun, M., Ahmad, N., Waqas, M., Kang, S. M., Kim, Y. H., et al. 2011. Exophiala sp. LHL08 reprograms Cucumis sativus to higher growth under abiotic stresses. Physiol. Plant. 143:329-343.

Khan, A. L., Hamayun, M., Waqas, M., Kang, S. M., Kim, Y. H., Kim, D. H., et al. 2012. Exophiala sp. LHL08 association gives heat stress tolerance by avoiding oxidative damage to cucumber plants. Biol. Fertil. Soils 48: 519-529.

Kim, D. G., and Riggs, R. D. 1994. Techniques for isolation and evaluation of fungal parasites of Heterodera glycines. J. Nematol. 26:592-595.

Koenning, S. R., and Wrather, J. A. 2010. Suppression of soybean yield potential in the continental United States by plant diseases from 2006 to 2009. Online publication. Plant Health Prog. doi: 10.1094/PHP-2010-1122-01RS.

Konietschke, F., Placzek, M., Schaarschmidt, F., and Hothorn, L. A. 2015. nparcomp: An R software package for nonparametric multiple comparisons and simultaneous confidence intervals. J. Stat. Softw. 64:1-17.

Kruskal, W. H., and Wallis, W. A. 1952. Use of ranks in one-criterion variance analysis. J. Am. Stat. Assoc. 47:583-621.

Lareen, A., Burton, F., and Schäfer, P. 2016. Plant root-microbe communication in shaping root microbiomes. Plant Mol. Biol. 90:575-587.

Latch, G. C. M. 1993. Physiological interactions of endophytic fungi and their hosts. Biotic stress tolerance imparted to grasses by endophytes. Agric. Ecosyst. Environ. 44:143-156.

Lee, M. J., Lee, H. N., Han, K., and Kim, E. S. 2008. Spore inoculum optimization to maximize cyclosporin A production in Tolypocladium niveum. J. Microbiol. Biotechnol. 18:913-917.

Legendre, P., and Gallagher, E. D. 2001. Ecologically meaningful transformations for ordination of species data. Oecologia 129:271-280.

Lević, J., Petrović, T., Stanković, S., and Ivanović, D. 2013. The incidence of Pyrenochaeta terrestris in root of different plant species in Serbia. Matica Srp. J. Nat. Sci. 51:21-30.

Li, F., Chen, L., Redmile-Gordon, M., Zhang, J., Zhang, C., Ning, Q., et al. 2018. Mortierella elongata's roles in organic agriculture and crop growth promotion in a mineral soil. L. Degrad. Dev. 29:1642-1651.

Li, J., Zou, C., Xu, J., Ji, X., Niu, X., Yang, J., et al. 2015. Molecular mechanisms of nematode-nematophagous microbe interactions: Basis for biological control of plant-parasitic nematodes. Annu. Rev. Phytopathol. 53:67-95.

Liu, X. Z., and Chen, S. Y. 2002. Nutritional requirements of the nematophagous fungus Hirsutella rhossiliensis. Biocontrol Sci. Technol. 12: 381-393.

Lundberg, D. S., Lebeis, S. L., Paredes, S. H., Yourstone, S., Gehring, J., Malfatti, S., et al. 2012. Defining the core Arabidopsis thaliana root microbiome. Nature 488:86-90.

Mahadevakumar, S., Jayaramaiah, K. M., and Janardhana, G. R. 2014. First report of leaf spot disease caused by Epicoccum nigrum on Lablab purpureus in India. Plant Dis. 98:284.

Malapi-Wight, M., Salgado-Salazar, C., Demers, J., Veltri, D., and Crouch, J. A. 2015. Draft genome sequence of Dactylonectria macrodidyma, a plant-pathogenic fungus in the Nectriaceae. Genome Announc. 3:e0027815 .

Manzanilla-Lopez, R. H., Esteves, I., Finetti-Sialer, M., Hirsch, P., Ward, E., Devonshire, J., et al. 2013. Pochonia chalamydosporia: Advances and challenges to improve its performance as a biological control agent of sedentary endo-parasitic nematodes. J. Nematol. 45:1-7.

Mao, W., Carroll, R. B., and Whittington, D. P. 1998. Association of Phoma terrestris, Pythium irregulare, and Fusarium acuminatum in causing red root rot of corn. Plant Dis. 82:337-342.
Mascarin, G. M., Ferreira, M., and Vieira de Araújo, J. 2012. Trichoderma harzianum reduces population of Meloidogyne incognita in cucumber plants under greenhouse conditions. J. Entomol. Nematol. 4:54-57.

Massalha, H., Korenblum, E., Malitsky, S., Shapiro, O. H., and Aharoni, A. 2017. Live imaging of root-bacteria interactions in a microfluidics setup. Proc. Natl. Acad. Sci. USA 114:4549-4554.

Massoud, S., Meyer, S. L. F., Roberts, D., and Chitwood, D. 2000. Evaluation of Trichoderma virens and Burkholderia cepacia for antagonistic activity against root-knot nematode, Meloidogyne incognita. Nematology 2: 871-879.

Mayer, A., Kilian, M., Hoster, B., Sterner, O., and Anke, H. 1999. In-vitro and in-vivo nematicidal activities of the cyclic dodecapeptide omphalotin A. Pestic. Sci. 55:27-30

McMurdie, P. J., and Holmes, S. 2013. Phyloseq: An R package for reproducible interactive analysis and graphics of microbiome census data. PLoS One 8:e61217.

Meyer, S., Huettel, R., and Sayre, R. 1990. Isolation of fungi from Heterodera glycines and in vitro bioassays for their antagonism to eggs. J. Nematol. 22: 532-537.

Meyer, S. L. F. 2018. Bioactive metabolites: Capitalizing on naturally derived nematode-antagonistic activity. J. Nematol. 50:647.

Najafzadeh, M. J., Suh, M. K., Lee, M. H., Ha, G. Y., Kim, J. R., Kim, T. H., et al. 2013. Subcutaneous phaeohyphomycosis caused by Exophiala equina, with susceptibility to eight antifungal drugs. J. Med. Microbiol. 62:797-800.

Nilsson, R. H., Larsson, K. H., Taylor, A. F. S., Bengtsson-Palme, J., Jeppesen, T. S., Schigel, D., et al. 2019. The UNITE database for molecular identification of fungi: Handling dark taxa and parallel taxonomic classifications. Nucleic Acids Res.: D259-D264.

O’Donnell, K., Ward, T. J., Robert, V. A. R. G., Crous, P. W., Geiser, D. M., and Kang, S. 2015. DNA sequence-based identification of Fusarium: Current status and future directions. Phytoparasitica 43:583-595.

Oksanen, J., Blanchet, F., Kindt, R., Legendre, P., Minchin, P., O'Hara, R., et al. 2016. Vegan: Community ecology package. R package version 2.3-4. https://cran.r-project.org/web/packages/vegan/index.html

Orole, O. O., and Adejumo, T. O. 2011. Bacterial and fungal endophytes associated with grains and roots of maize. J. Ecol. Nat. Environ. 3:298-303.

Osorio, N. W., and Habte, M. 2014. Soil phosphate desorption induced by a phosphate-solubilizing fungus. Commun. Soil Sci. Plant Anal. 45:451-460.

Papademetriou, M. K., and Bone, L. W. 1983. Chemotaxis of larval soybean cyst nematode, Heterodera glycines race 3, to root leachates and ions. J. Chem. Ecol. 9:387-396.

Park, J. O., Hargreaves, J. R., McConville, E. J., Stirling, G. R., Ghisalberti, E. L., and Sivasithamparam, K. 2004. Production of leucinostatins and nematicidal activity of Australian isolates of Paecilomyces lilacinus (Thom). Samson. Lett. Appl. Microbiol. 38:271-276.

Potshangbam, M., Indira Devi, S., Sahoo, D., and Strobel, G. A. 2017. Functional characterization of endophytic fungal community associated with Oryza sativa L. and Zea mays L. Front. Microbiol. 8:1-15.

Preston, J. F., Dickson, D. W., Maruniak, J. E., Nong, G., Brito, J. A., Schmidt, L. M., et al. 2003. Pasteuria spp.: Systematics and phylogeny of these bacterial parasites of phytopathogenic nematodes. J. Nematol. 35:198-207.

Redman, R. S., Dunigan, D. D., and Rodriguez, R. J. 2001. Fungal symbiosis from mutualism to parasitism: Who controls the outcome, host or invader? New Phytol. 151:705-716.

Redman, R. S., Kim, Y. O., Woodward, C. J. D. A., Greer, C., Espino, L., Doty, S. L., et al. 2011. Increased fitness of rice plants to abiotic stress via habitat adapted symbiosis: A strategy for mitigating impacts of climate change. PLoS One 6:e14823.

Renuka, S., and Ramanujam, B. 2016. Fungal endophytes from maize (Zea mays L.): Isolation, identification and screening against maize stem borer, Chilo partellus (Swinhoe). J. Pure Appl. Microbiol. 10:523-528.

Riga, E., Topp, E., Potter, J., Welacky, T., Anderson, T., and Tenuta, A. 2001. The impact of plant residues on the soybean cyst nematode, Heterodera glycines. Can. J. Plant Pathol. 23:168-173.

Rinu, K., Sati, P., and Pandey, A. 2014. Trichoderma gamsii (NFCCI 2177): A newly isolated endophytic, psychrotolerant, plant growth promoting, and antagonistic fungal strain. J. Basic Microbiol. 54:408-417.

Rothen, C., Miranda, V., Aranda-Rickert, A., Fracchia, S., and Rodríguez, M. A. 2017. Characterization of dark septate endophyte fungi associated with cultivated soybean at two growth stages. Appl. Soil Ecol. 120:62-69.

Russo, M. L., Pelizza, S. A., Cabello, M. N., Stenglein, S. A., Vianna, M. F., and Scorsetti, A. C. 2016. Endophytic fungi from selected varieties of soybean (Glycine max L. Merr.) and corn (Zea mays L.) grown in an agricultural area of Argentina. Rev. Argent. Microbiol. 48:154-160.

Sahebani, N., and Hadavi, N. 2008. Biological control of the root-knot nematode Meloidogyne javanica by Trichoderma harzianum. Soil Biol. Biochem. 40:2016-2020

Sasse, J., Martinoia, E., and Northen, T. 2018. Feed your friends: Do plant exudates shape the root microbiome? Trends Plant Sci. 23:25-41. 
Schouten, A. 2016. Mechanisms involved in nematode control by endophytic fungi. Annu. Rev. Phytopathol. 54:121-142.

Schulz, B., and Boyle, C. 2005. The endophytic continuum. Mycol. Res. 109: 661-686.

Seaman, W. L., Shoemaker, R. A., and Peterson, E. A. 1965. Pathogenicity of Corynespora cassiicola on soybean. Can. J. Bot. 43:1461-1469.

Seifert, C. A., Roberts, M. J., and Lobell, D. B. 2017. Continuous corn and soybean yield penalties across hundreds of thousands of fields. Agron. J. 109:541-548.

Sharon, E., Chet, I., Viterbo, A., Bar-Eyal, M., Nagan, H., Samuels, G. J., et al. 2007. Parasitism of Trichoderma on Meloidogyne javanica and role of the gelatinous matrix. Eur. J. Plant Pathol. 118:247-258.

Siddiqui, I. A., and Shaukat, S. S. 2003. Non-pathogenic Fusarium solani represses the biosynthesis of nematicidal compounds in vitro and reduces the biocontrol of Meloidogyne javanica by Pseudomonas fluorescens in tomato. Lett. Appl. Microbiol. 37:109-114.

Soil Survey Staff. 2014. Keys to Soil Taxonomy, 12th ed. U.S. Department of Agriculture Natural Resources Conservation Service, Washington, DC.

Stiles, C., and Glawe, D. 1989. Colonization of soybean roots by fungi isolated from cysts of Heterodera glycines. Mycologia 81:797-799.

Strobel, G., and Daisy, B. 2003. Bioprospecting for microbial endophytes and their natural products. Microbiol. Mol. Biol. Rev. 67:491-502.

Strom, N. B., Hu, W., Bushley, K. E., and Chen, S. 2019a. Continuous monoculture shapes root and rhizosphere fungal communities of corn and soybean in soybean cyst nematode-infested soil. Phytobiomes J. 3:300-314.

Strom, N. B., Hu, W., Haarith, D., Chen, S., and Bushley, K. 2019b. Fungal communities in soybean cyst nematode-infested soil under long term corn and soybean monoculture and crop rotation. bioRxiv 516575 .

Summerbell, R. C. 2001. Respiratory tract infections caused by indoor fungi. Pages 279-308 in: Microorganisms in Home and Indoor Work Environments. B. Flannigan, R. Samson, and J. Miller, eds. CRC Press, London, UK.

Suryanarayanan, T. S., Thirunavukkarasu, N., Govindarajulu, M. B., Sasse, F., Jansen, R., and Murali, T. S. 2009. Fungal endophytes and bioprospecting. Fungal Biol. Rev. 23:9-19.

United Nations Environment Programme. 2015. Montreal Protocol on Substances That Deplete the Ozone Layer: 2014 Report of the Methyl Bromide Technical Options Committee. United Nations Environment Programme, Nairobi, Kenya.

Valent BioSciences. 2010. DiTera biological nematicide. https://www. valentbiosciences.com/cropprotection/wp-content/uploads/sites/2/2017/03/ ditera-brochure-ag-54241.pdf

van de Voorde, T. F. J., van der Putten, W. H., and Martijn Bezemer, T. 2011. Intra- and interspecific plant-soil interactions, soil legacies and priority effects during old-field succession. J. Ecol. 99:945-953.

Van Overbeek, L., and Van Elsas, J. D. 2008. Effects of plant genotype and growth stage on the structure of bacterial communities associated with potato (Solanum tuberosum L.). FEMS Microbiol. Ecol. 64:283-296.
Waller, F., Achatz, B., Baltruschat, H., Fodor, J., Becker, K., Fischer, M., et al. 2005. The endophytic fungus Piriformospora indica reprograms barley to salt-stress tolerance, disease resistance, and higher yield. Proc. Natl. Acad. Sci. 102:13386-13391.

Wang, N., Zhang, Y., Jiang, X., Shu, C., Imran Hamid, M., Hussain, M., et al. 2016. Population genetics of Hirsutella rhossiliensis, a dominant parasite of cyst nematode juveniles on a continental scale. Appl. Environ. Microbiol. 82:6317-6325.

Warnock, N. D., Wilson, L., Patten, C., Fleming, C. C., Maule, A. G., and Dalzell, J. J. 2017. Nematode neuropeptides as transgenic nematicides. PLoS Pathog 13:e1006237.

Westphal, A., Li, C., Xing, L., McKay, A., and Malvick, D. 2014. Contributions of Fusarium virguliforme and Heterodera glycines to the disease complex of sudden death syndrome of soybean. PLoS One 9:e99529.

Wilcoxon, F. 1945. Individual comparisons by ranking methods. Int. Biometric Soc. $1: 80-83$.

Wilman, K., Stępień, Ł., Fabiańska, I., and Kachlicki, P. 2014. Plantpathogenic fungi in seeds of different pea cultivars in Poland. Arh. Hig. Rada Toksikol. 65:329-338.

Wilson, M. J., and Jackson, T. A. 2013. Progress in the commercialisation of bionematicides. BioControl 58:715-722.

Yadav, V., Kumar, M., Deep, A. K., Kumar, H., Sharma, R., Tripathi, T., et al. 2010. A phosphate transporter from the root endophytic fungus Piriformospora indica plays a role in phosphate transport to the host plant. J. Biol. Chem. 285:26532-26544.

Yamaji, K., Watanabe, Y., Masuya, H., Shigeto, A., Yui, H., and Haruma, T. 2016. Root fungal endophytes enhance heavy-metal stress tolerance of Clethra barbinervis growing naturally at mining sites via growth enhancement, promotion of nutrient uptake and decrease of heavy-metal concentration. PLoS One 11:e0169089.

Yang, H., Ye, W., Ma, J., Zeng, D., Xu, M., Wang, Y., et al. 2018. Endophytic fungal communities associated with field-grown soybean roots and seeds in the Huang-Huai region of China. PeerJ 6:e4713.

Yu, Z., Mo, M., Zhang, Y., and Zhang, K.-Q. 2014. Taxonomy of nematodetrapping fungi from Orbiliaceae, Ascomycota. Pages 41-210 in: Nematode Trapping Fungi. K.-Q. Zhang and K. D. Hyde, eds. Springer, Dordrecht, Netherlands.

Zhang, L., Yang, E., Xiang, M., Liu, X., and Chen, S. 2008. Population dynamics and biocontrol efficacy of the nematophagous fungus Hirsutella rhossiliensis as affected by stage of the soybean cyst nematode. Biol. Control 47:244-249.

Zhang, N., O'Donnell, K., Sutton, D. A., Nalim, F. A., Summerbell, R. C., Padhye, A. A., and Geiser, D. M. 2006. Members of the Fusarium solani species complex that cause infections in both humans and plants are common in the environment. J. Clin. Microbiol. 44:2186-2190.

Zhang, Y., Crous, P. W., Schoch, C. L., and Hyde, K. D. 2012. Pleosporales. Fungal Divers. 53:1-221. 